\title{
Mutual interactions between cognition and welfare: the horse as an animal model
}

M. Hausberger ${ }^{1}$, M. Stomp*2, C. Sankey ${ }^{3}$, S. Brajon ${ }^{4}$, C. Lunel ${ }^{5}$, S. Henry ${ }^{2}$

1 CNRS, Laboratoire d'Ethologie animale et humaine, UMR6552, Université de Rennes, Université de Caen-Normandie, Campus de Beaulieu, Avenue du Général Leclerc, 35042 Rennes Cedex, France

2 Université de Rennes, Laboratoire d'Ethologie animale et humaine, UMR 6552, CNRS, Université de Caen-Normandie, Station Biologique, 35380 Paimpont, France

3 Université Paris Descartes, Sorbonne Paris Cité, Institut de Psychologie, Laboratoire de Psychopathologie et Processus de Santé (EA 4057), France

4 Université Laval, Départment des Sciences Animales, Ville de Québec, Québec, Canada

5 IGEPP, Agrocampus Ouest, INRA, Université de Rennes, Université Bretagne-Loire, Rennes, France

*Corresponding author, martine.hausberger@univ-rennes1.fr

Highlights

- Individual characteristics such as temperament or stereotypies influence learning

- Vertebral problems, depression and anemia lower attentional and sensory engagement

- Type of training/reinforcement influences cognition, welfare and motivation to work

- Brain lateralization and EEG are promising tools for measuring cognition and welfare

- Evolution of brain functions and life conditions are influential in shaping cognition

\begin{abstract}
Research in cognitive psychology has repeatedly shown how much cognition and emotions are mutually related to one another. Psychological disorders are associated with cognitive (attention, memory and judgment) biases and chronic pain may affect attention, learning or memory. Laboratory studies have provided useful insights about the processes involved but observations about spontaneous animal models, living in different stress/welfare conditions may help understand further how cognition and welfare are interrelated in the " real world ». Domestic horses constitute such a model as they live in a variety of conditions that impact
\end{abstract}


differently their welfare state. In the present review, we try and provide an overview of the scientific literature on cognition and welfare of domestic horses and their interrelationship. We address how emotions and welfare may affect cognitive processes in horses and impact the way they perceive their environment (including work). We propose new methods for assessing the relationship between welfare and cognition and open up the discussion on the evolution of the brain and the part domestication may have played.

\section{INTRODUCTION}

"Cognitive psychology is concerned with the internal mental processes that begin with the appearance of an external stimulus and result in a behavioural response" (Hopfinger and Mangun, 2001). There are two reasons why the study of cognitive processes has been extensively developed in the last decades in animal models: One is related to the objectives of comparative psychology, aiming to seek parallels between human and animal cognition, in order to better understand cognitive processes (e.g. Roitblat et al., 1984; Timberlake, 1990). The other is related to the objectives of cognitive ethology, aiming at understanding cognitive processes as a response to the ethological and ecological constraints, in particular over evolution (e.g. Griffin, 1984; Yoerg and Kamil, 1991). In both cases, studies of animal cognition aim at understanding "the way animals perceive, process, acquire, store and act upon information coming from their environment" (Shettleworth, 1998).

There is extensive evidence that emotions and cognition are interrelated. The term emotion arises from latin « ex movere »: «going out » of the normal state. The existence of emotions has been mentioned since antiquity and later by Darwin in his 1872 book where he proposes that animal and human emotions form a continuum. There have been different definitions of emotions (Boissy et al., 2007; Clore et al., 1994; Dantzer, 1988; Panksepp, 2005; Paul et al., 2005) but they all converge towards the definition we will rely upon in this review: short-lived affective responses, pleasant or painful, elicited by internal or external sudden changes, associated with specific body changes and that provide animals the ability to avoid punishment or to seek valuable resources (Boissy et al., 2007). Negative emotions such as fear, anger or frustration can be induced by a threat, an aggression, the loss of a social partner or the difficulty to reach a valuable resource (Reid et al., 2017; von Borstel et al., 2010; Yngvesson et al., 2016), whether events are actual or expected, and drive animals to avoid or solve those situations. Alternatively, positive emotions can be induced by the removal of a threat/aggression, the 
reunion with social partners or the reception of favoured items (Olczaka et al., 2018), whether events are actual or expected, and drive animals to seek valuable resources or positive situations. Emotion arises according to the way the individual evaluates and perceives the event rather than the event itself (Boissy \& Erhard, 2014). As such, emotional experiences may differ between individuals according to their intrinsic characteristics such as their breed, sex, age, temperament but also their own experience. Emotionality, also called emotional reactivity, is the propensity of individuals to react to challenging situations with high behavioural reactions (e.g. body shaking, whinny) associated with intense physiological responses (e.g. increase in heart rate)(e.g. Kozak et al., 2018). According to "affective neuroscience", the basic emotional circuits of mammalian brains show consistency along the evolutionary scale and studying the basic emotional systems of animals may help scientifically understand the foundations of the human mind (Panksepp, 2011b). The neuronal basis of the emotions has been explored and brain structures have been identified as being involved in the perception of stimuli (i.e., sensory cortex, Soudry et al., 2011; Grosso et al., 2015; Concina et al., 2019), processing and storage of the information (e.g., orbitofrontal cortex, amygdala and hippocampus; LeDoux, 2000; Barbas et al., 2011; Chaaya et al., 2018; Rolls, 2019), and expression of emotions (e.g., paraventricular nucleus of the hypothalamus that triggers endocrine responses, periaqueductal gray that triggers behavioural responses and medulla that triggers autonomic responses, Hagemann et al., 2003; Goldstein, 2010; Menant et al., 2016, 2018). Panksepp (2005, 2011a) has mapped several basic emotional circuits in mammals consisting of neuronal pathways that interconnect midbrain circuits concentrated in midbrain regions, such as periaqueductal gray, with various basal ganglia, such as amygdala, via the hypothalamus and thalamus. The emotional systems appear to be highly conserved among all mammalian species, which makes knowledge derived from rodents applicable for all other mammals, including humans. For instance, the SEEKING system, also referred as the "mesolimbic dopamine system" or the "brain reward system", involves dopaminergic pathways that connect limbic structures to associative and motor neural areas and courses from ventral midbrain to nucleus accumbens and frontal cortex (Alcaro and Panksepp, 2011). The activation of this system drives explorative and reward-seeking behaviours (e.g. locomotion and sniffing in rat), and triggers excitement and positive emotions. Taking psychoactive drugs, such as cocaine or amphetamine, in humans exacerbates the dopamine secretion and its effect on motivation behaviour, leading to highly energized and impulsive behavioursand positive emotions, with the escalating goal of obtaining more and more valuable rewards (Trifilieff et al., 2017). In contrast, apathy, a symptom of depression that is characterised by a reduced motivated decision-making, may be related to a 
hypoactivity of the SEEKING system (for a review in humans: Chong, 2018). The SEEKING system is often opposed to the well-known FEAR system, also called "avoidance system", whose main circuitry basically courses between basolateral and central regions of the amygdala and descends through the hypothalamus to the periaqueductal gray of the midbrain (Panksepp, 2011b). The stimulation of this system evokes fearful psychological states in humans while it induces freezing and flight behaviours as well as autonomic responses in non-human animals (Panksepp, 2011b). Beyond this approach of "discrete emotions", the "dimensional" approach plots emotions in a two-dimensonial space along an affective valence axis and intensity axis (Russell,1980; Makovska \& Weary, 2013). Valence refers to the positive or negative aspect of emotions while intensity refers to the arousal level. Mendl et al. (2010) have proposed a framework that integrates these two approaches and allows for the representation in twodimensional space of affective states resulting from the interaction between discrete emotions, such as short-term responses to specific stimuli, and longer term background mood.

In humans, cognitive experimental manipulations have been shown to influence affective experiences of subjects via their influence on how significant events are processed (Mathews and MacLeod, 2002). On the other hand, cognitive alterations were found in studies where individuals' affective states were manipulated (Forgas, 2000; Hinde, 1985). According to the appraisal theory (Scherer, 1984, Scherer, 2005), emotions arise through an evaluation of the relevance of perceptual information to the organism at the present time. Based on this process, a specific valence (+/-) is attributed to the emotion experienced (Lerner and Keltner, 2000). Given the individuals' affective state, cognitive biases may interfere with this evaluation (Mathews and MacLeod, 1994; Mineka et al., 1998). Thus, many studies, mainly based on experimental research using linguistic stimuli, e.g. words with either threatening or neutral meanings, highlighted that people suffering from affective disorders (e.g. depression, anxiety) were more prone to process preferentially negative stimuli (e.g. Matthews and Antes, 1992; Williams et al., 1997).

There are ethical implications in the finding that animals, in particular domestic animals, like humans, experience affective states: the way they are managed and its consequences on their welfare, is related to their abilities to experience fear, pain, hunger or thirst (Panksepp, 2011b). There have been many definitions of welfare: the more classical definitions mention welfare as an internal physiological balance (Broom, 1991: Friend, 1991), a satisfaction of behavioural needs (Dawkins, 1990, Duncan, 1998), an absence of negative emotions and presence of 
positive emotions (Duncan, 1998; Fraser, 1993). All definitions agree that it is a chronic subjective state and that it is crucial to consider animal-based criteria rather than just observations of the conditions of life (Blokhuis et al., 2003; Whay et al., 2003; Wood et al., 1998).

In the present study, we will apply the following definition of welfare which takes into account all aspects mentioned by former definitions: « a chronic positive mental and physical state resulting from the satisfaction of the animal's behavioural and physiological needs and expectations . This state can vary according to the perception of the situation by the animal » (e.g. ANSES 2018) Agence nationale de sécurité sanitaire de l'alimentation, de l'environnement et du travail, saisie $n^{\circ}$ 2016-SA-0288),

In humans, compromised welfare states, whether related to physical or psychological problems, are associated with cognitive disturbances. Clinical depression is associated with deficits in selective attention (i.e. ability to focus perception on one stimulus while filtering out other simultaneous stimuli) (Posner et al., 1980), which may be due to a disruption of attention by the negative emotional state (de Williams, 2002; Smith et al., 1985) or to deficits in engaging in effortful cognitive processes such as focusing on relevant stimulations (Gotlib and Joormann, 2010). Lastly, chronic pain is thought to affect patients' cognitive functioning in domains such as attention (e.g. Eccleston, 1994), learning or memory (Hart et al., 2000), which may be due to the fact that pain is an inherently attention-demanding sensory process (Bantick et al., 2002). Overall, beyond clinical alterations, background affective states do influence a number of cognitive processes, inducing biases in information processing (e.g. Paul et al., 2005). Cognitive biases have been argued to be central to the evolutionary function of moods, and it « is therefore reasonable to expect them to be present across species » (Nettle and Bateson, 2012).

Laboratory animal models have been used to model these relationships between anxiety, depression or chronic pain and cognitive impairments (e.g. Pais-Vieira et al., 2009). Such laboratory studies have revealed that fear, anxiety or depression have a genetic component and that selection on traits such as anxiety can be performed successfully on rats (e.g. Gray 1987, Henninger et al., 2000) and allowed to identify drugs (e.g. diazepam) that may reduce them Thus, anxious rats (having received non-contingent foot shock) self-administer cocaine (Goeders and Guerin, 1994) and anxiolytics (Cook and Davidson, 1973). Housing conditions influence morphine consumption in rats, probably because of its anxiolytic effects (Makovska \& Weary, 2013). 
Indeed, some studies have demonstrated that barren housing conditions of laboratory mice constraint brain development and behaviour: efforts made to put animals under highly controlled environments and to standardize experiments (in order to increase reproducibility) may ironically be associated with poor external validity (Würbel 2000, 2001). This is why studies of the spontaneous emergence of such disorders in the daily environment of animals would have a high external validity and could help advance the understanding of these mutual relationships.However, studies of the spontaneous emergence of such disorders in the daily environment of animals are still mostly missing. The daily loss of attention paid to their environment by humans in chronic pain or depression is not assessed by clinical studies and thus appears only through self-reports. The extent chronic pain or negative affective states affect attentional engagement in the daily life remains unknown. This is where spontaneous animal models could be of great help. Thus, some studies have shown that tryptophan administration may modulate the behavioural and physiological responses of horses to acute stress due to social isolation (e.g. Bagshaw et al., 1994).

Companion or working animals, like humans, undergo " education » and training, whose success and impact on the affective state may depend not only on the training strategy but also on welfare conditions (e.g. Haverbeke et al., 2008). Clarifying how training and work may both interfere with and depend on the welfare state is an issue that observation of domestic animals in these spontaneous contexts may help clarifying.

Besides, the extent to which evolutionary processes/ domestication and conditions of life impact the interrelationship between welfare and cognition is a fundamental issue in our understanding of the evolution of human and animal adaptability.

In this regard, the domestic horse is a very interesting and rather unique model. Intermediate between farm and companion animals, horses are expected to present appropriate cognitive responses to human demands, whether in terms of individual interactions with their owner or in a training context. Also, "Clever Hans" (Pfungst 1911), has been an emblematic figure of domestic animals'cognitive use of human signals: after it was believed that this famous horse was able to count, thorough observations revealed that in fact, he was reacting to very subtile unconscious body movement of his owner. Moreover, horses share working environments with humans. This provides the opportunity to assess the impact of the welfare state on the daily cognitive investment and to have a "field" view that allows to progress beyond the classical experimental models, and hence to propose new lines of though that go beyond the sole horse cognition question. To date, some detailed reviews have been published on horse perception ( 
Hausberger and Henry, 2018; Leblanc, 2010; Saslow, 2002), learning ( Brubaker and Udell, 2016; Murphy and Arkins, 2007; Nicol, 2002), and overall cognitive abilities (e.g. Krueger et al., 2017; Leblanc, 2010). However, none have tackled the question of the potential mutual relationship with welfare. The aim of this review is thus to provide an overview of the existing scientific literature on cognition and welfare of domestic horses and a better understanding on how these areas are interrelated. We will try to disentangle the factors involved, including evolutionary considerations. After briefly introducing the horse as an animal model for cognitive studies, we first address how short-lived emotions and then chronic welfare conditions and state (including physical health and physiological aspects) affect cognitive processes such as learning, memory and attention in domestic horses. The impact these factors have on the way horses perceive their environment (including humans and training/work) is addressed. We then examine how the study of the cognitive abilities of horses may help find practical ways to promote positive emotions and a better welfare state under domestic conditions. All these aspects are considered in a comparative way and new perspectives about evolutionary processes are proposed.

\section{COGNITIVE ABILITIES OF HORSES: FACTS AND EVOLUTIONARY CONSIDERATIONS}

During the course of the evolution of horses' cephalization, there has been an increase of brain size independent from that of body size, as well as a differentiation of important areas for cognition, e.g. cortex, striatum (Röhrs and Ebinger, 1993). Perceptual and cognitive abilities reflect in horses, as in other domestic and non-domestic species, the challenges species have faced during the evolutionary process (Krueger et al., 2017; Roitblat and von Fersen, 1992; von Uexküll, 1965). Horses, like sheep, are permanent steppe grazers and have to deal with sparse and varied food; they prefer spatial over visual object-specific cues for finding food, they have taste aversions which prevent them from being poisoned, and they are able to associate the characteristics of food with immediate (less than $30 \mathrm{~min}$ ) post-ingestive consequences (Cairns et al., 2002; Dumont and Boissy, 1999; Hothersall et al., 2010 ; Houpt et al., 1990; Pfister et al., 2002). Living on large home ranges (up to $200 \mathrm{~km}^{2}$ ), where different areas provide different resources (food, shelter, rolling), horses have developed spatial abilities, although they may not always succeed in detours (e.g. Baragli et al., 2011; Kabadayi et al., 2018; Waring, 2003; Wolff and Hausberger, 1996). Overall, as in many other species (e.g. pigeons), rats, cognitive studies in horses have revealed that they are able to discriminate (Hanggi and Ingersoll, 2009), and 
categorize visual stimuli (e.g. shape) (Hanggi, 1999), generalize to new exemplars (e.g. Hanggi, 2005), evaluate quantities (Uller and Lewis, 2009), and they might even have the ability to form concepts such as the concept of relative size (Hanggi, 2003) or of same-different: while habituating a horse to a specific novel object will reduce its response, the fear response remains when it is confronted with a totally different novel object (Leiner \& Fendt, 2011).

A remarkable and well-known feature of horse cognitive ability is long term-memory. Several studies have demonstrated that horses are able to repeat a task that has been learnt one week (spatial task, Marinier and Alexander, 1994), one month (instrumental and detour tasks, Wolff and Hausberger, 1996), 5 to 12 months (Gardner, 1933; Henry et al., 2005; Sankey et al., 2010b, c), 22 months (instrumental and avoidance tasks, Valenchon et al., 2013b), and up to 6 to 10 years (discrimination, categorization: Hanggi and Ingersoll, 2009), later, without error. Interestingly, there does not seem to be a "general learning ability" as no correlation was found between different types of learning: instrumental versus spatial (Wolff and Hausberger, 1996; Le Scolan et al., 1997), avoidance versus instrumental (Visser et al., 2003; Lansade \& Simon, 2010), or discrimination reversal learning versus performance task (Sappington et al., 1997). Capacities for "higher" cognitive skills such as self-recognition (Baragli et al., 2017a) or imitative learning (or even mere observational learning) (e.g. Ahrendt et al., 2012; Baker and Crawford, 1986; Clarke et al., 1996; Lindberg et al., 1999; Rørvang et al., 2015) have not yet been clearly demonstrated in horses though (but see Krueger et al., 2014).

The evolution of sociality has been associated with that of social cognition, i.e. special skills that maintain cohesion and avoid costly conflict (Aureli and de Waal, 2000). For some authors, social bonding in mammals is based upon the same processes involved in mother-young bonding: in both cases, the same neurochemicals, especially oxytocin and endogenous opioids, but also prolactin, are involved (CARE and PANIC systems) (Panksepp, 2011b). Thus, sociality is based on interattraction and distress when isolated (isolation syndrome) (e.g. Grassé, 1963; Lihoreau et al., 2009), but differs from gregariousness by involving reciprocal communication and influences between the individuals constituting the group (e.g. Grassé, 1963; Hinde, 1976). Hinde (1979) has described the different levels of society from individual characteristics to the establishment of relationships: social organization is based on this network of relationships, but varies also between species which may differ in terms of "social disposition" (Mason, 1978). In natural conditions, horses, like most ungulates, live in stable groups with a well defined but little expressed hierarchy and clear social preferences that are 
mostly expressed through spatial proximity, a feature shared with many species (Feh 2005; Hausberger et al., 1995; Mason, 1978).

Social organization is thus based on social cognition, and it is considered that the "social brain" and the "cognitive brain" are interrelated (Kuhl, 2003). Thus, like most tested social vertebrates, horses are able to use unimodal and multimodal discrimination and recognition of familiar group members to detect their attentional state but also possibly to withdraw information from dominant conspecifics (e.g. Andrieu et al., 2016; Lemasson et al., 2009; Wathan and McComb, 2014). Acoustic signals encode information on the sender's identity, physical characteristics, familiarity, sex and even emotional or fertility status (Briefer et al., 2015; Lemasson et al., 2009, 2015a, 2015b; Stomp et al., 2018). This knowledge of both the identity and social status of different group members allows stable groups to spend little energy in useless agonistic encounters (e.g. Fureix et al., 2012a). These social cognitive abilities, however, require some "training" which means horses, like humans (e.g. West et al., 2003) and other non-human species (e.g. elephants: Slotow et al. 2000), also have to learn the social rules, mostly at a young age, through adult modelling (e.g. Bourjade et al., 2009). Receivers clearly decode this information and different studies have revealed that the corresponding brain processes are lateralized, horses showing a left visual bias (right hemisphere) for agonistic encounters (Austin and Rogers, 2014) and a right ears orientation bias (left hemisphere) for familiar whinnies (Basile et al., 2009). Horses thus follow the evolutionary rules described in the "valence theory" which reveals that most animals (and humans) show a right hemisphere bias to process fearinducing and threatening stimuli and a left hemisphere bias to process familiar stimuli (e.g. Davidson, 1992; Rogers and Andrew, 2002; Russell and Barrett, 1999; Vallortigara and Rogers, 2005; Watson et al., 1999).

The visual system of the horse with its panoramic field (with two large monocular fields and a restricted frontal binocular field of $40-60^{\circ}$ ) is similarly well adapted to precisely detect food items on the ground. Brain decussation of the optic fibres is almost complete in horses, with up to $80-90 \%$ of the fibres crossing in the corpus callosum, which means that hemispheric specialization may be particularly crucial in this species (Herron et al., 1978). Flight is the most frequent response to predation although stallions and other adults may face and attack predators and groups of adults can put themselves in a circle and defend themselves by kicking (Boyd and Keiper, 2005) and attacking them (Waring, 2003). Aggression is therefore another possible response to predators. 
Horses tend to react with high short-lived emotions to fear-inducing signals. Fear induces postural (vigilance, tail raised), locomotory (trot, canter, prancing) changes, and sometimes vocal (snoring, blows) responses that can be detected by group members (Kiley-Worthington, 1976; Waring, 2003). Social separation (even merely visual) leads to higher locomotory components (searching for the partner) and loud whinnies. These responses may aid social partners to be reunited (Waring, 2003).

While humans did hunt horses in the early ages, it is difficult to believe that nowadays domestic horses still perceive them as predators. Humans are often present from the earlier stages of a domestic horse's life and a foal may elicit investigative behaviours and interest if its mother has a good relationship with humans (Henry et al., 2005). Horses establish relationships with humanswhich are based over time on repeated interactions, like intraspecific relationships (Hausberger et al., 2008), and create positive or negative memories according to the valence of their interactions with humans (D'Ingeo et al., 2019; Waiblinger et al., 2006). They are able to discriminate human attentional (Proops and McComb, 2010; Sankey et al., 2011b) or emotional (on the basis of facial expressions: Smith et al., 2016) states and to build multisensory representations of familiar humans (Proops and McComb, 2010; Sankey et al., 2011a; Lampe and Andre, 2012). They can also respond to human signals such as pointing gestures (Maros et al., 2008; Krueger et al., 2011) although somewhat less well than dogs. They can even use referential gestures to manipulate the attention of a human recipient to obtain an unreachable resource (Malavasi and Huber, 2016). Establishing whether domestication and/or experience with humans underpin these abilities in horses remains a challenging issue for scientists.

Selective breeding may play a role on specific cognitive skills as studies have shown differences in the reactions to humans (Hausberger and Muller, 2002) or in learning abilities between breeds (Mader and Price, 1980; Budzynski et al., 1992; Lindberg et al., 1999) or offspring of different sires (Wolff and Hausberger, 1996). In a first attempt to evaluate heritability, Hausberger et al (2007) used the data of Hausberger et al (2004) on 703 horses from 16 breeds to calculate coefficients of heritability: they found the same coefficients for instrumental learning (opening a chest to find food) and for emotionality traits such as gregariousness or reactions to a fear-inducing novel object. It seems therefore that cognitive abilities have a genetic component as do temperamental traits. When considering only the 246 French Saddlebreds, the coefficient was of 0.48 for learning and 0.39 for the arena test (gregariousness) and 0.41 for the reactions to the fear-inducing object. Sex differences have rarely been found 
but Wolff and Hausberger (1996) observed that young females performed better at a detour task than young males, which they attributed to the more frequent movements initiated by females in natural groups. Using the same test, Le Scolan et al. (1997) found better performances in adult riding school horses than in younger unbroken animals still in their breeding farm. There is a confounding factor though, since age and training can both influence cognitive abilities (see below). Individual behavioral differences are indeed frequent and temperament, as an ensemble of individual characteristics with a relative stability across time and situations, is another influential factor on cognition. Thus, different cognitive strategies may be observed in individual detour solving tasks (Baragli et al., 2017b) and individual emotionality has been shown to influence learning and memory (Goldsmith et al., 1987, see below in the review).

\section{EFFECTS OF (SHORT-LIVED) EMOTIONS ON COGNITION}

Emotions, as "intense affective responses" (Dantzer, 1988) are short lived but the repetition of negative emotions is generally considered as a source of compromised welfare, which in turn further reinforces the negative emotions. This is particularly true for fear as there is a generalization from past experiences to future encounters: wheras generalization has an adaptive value, overgeneralization is maladaptive (Asok et al., 2019; Boissy 1995). Fear generalization particularly involves amygdalar, prefrontal, hippocampal and thalamic areas, which might be associated with different fear memories or time scales (Asok et al., 2019). On one hand, emotions and welfare result from a subjective perception of the current situation based on individual intrinsic characteristics, e.g. temperament, (Bates, 1989]), as well as experience. Cognition may thus influence the perceived state of welfare. On the other hand, durable affective states are known to induce cognitive biases in the way individuals perceive the current situation; welfare therefore influences cognitive processes (Mendl et al., 2010).

Understanding the link between short-lived emotions and cognition may thus help understand the processes underlying the mutual relationship between cognition and chronic welfare.

Overall, most studies agree on the negative influence of emotionality on learning performances, whatever the type of task (discrimination: Fiske and Potter, 1979; instrumental task, i.e. chest opening: Le Scolan et al., 1997 ; maze: Heird et al., 1986): with the most emotive animals being less performant. However, an influence of the type of task was found by Le Scolan et al. (1997), who showed that animals that crossed a "bridge" in a fear-handling task (bridge test) were more successful in an instrumental, but not in a spatial task compared to those that were more 
reluctant to cross the bridge (see also Hausberger et al., 2007b). Lansade et al. (2013) found that less reactive horses performed better in an instrumental task while the reactive horses performed better in a pavlovian type of task. Christensen et al. (2012) found that the predisposition to react to frightening stimuli (i.e. objects) was associated with decreased performances for a negative reinforcement task when horses were trained in a novel environment; but no such relationship was found for a task with positive reinforcement nor when the training took place in the familiar environment. One study even found that the most fearful horses learned an avoidance task better, while the least fearful horses learned an intrumental task better with positive reinforcement (Lansade and Simon, 2010). However, Christensen et al. (2012) argued that the observed correlation may relate more to fearfulness during the task than reflect a beneficial effect of fearfulness on learning. This converges with the fact that tactile sensitivity was positively correlated with resistance to extinction in this avoidance test, based on a negative reinforcement which consisted in an air puff fixed on a belt on the horse's body, hence acting directly on the horse's skin.

Valenchon et al. (2013c) applied, on two differents experimental groups, strong stressors during 30 minutes, before or after the acquisition session of an instrumental task (a third group served as a control). Eight days later, these horses were subjected to a reacquisition session without any stressor. The authors found firstly that the non-stressed horses (control group) were more efficient at the reacquisition phase (i.e. they improved their performance between acquisition and reacquisition sessions) and secondly that the temperament of horses (as assessed in a series of tests) was only influential on cognitive performances when they were tested under stressful conditions. Besides, when the stress procedure was performed after an acquisition session, the performance was improved in the least reactive horses (i.e. that startled less and whinnied less in all emotionality tests, thus considered as the least fearful and least gregarious). In the same line, Valenchon et al. (2013a) found that stressed horses had shorter delayed response for disappearing food (i.e. shorter working memory) especially if they had proven to be more fearful in temperament tests. Lansade et al. (2017), using a contingency degradation paradigm (reward associated with response versus reward independent of action), suggested that the most fearful horses would rely more upon the stimulus-response link (« automatic responses »), while the least fearful horses would logically be more sensitive to the response-outcome part.

Overall there is clearly an interplay between individual characteristics, the type of task, and the situation when training takes place. Stress and extraneous stimulations were recognized early on by Pavlov as disturbing learning when he built his "silence tower" (Pavlov 1904). The 
discrepancies between studies on temperament and cognition may reflect differences in the procedures and measures chosen, but also in the traits measured. In Le Scolan et al. (1997)'s study, neither the reactions to social separation nor to a novel object were predictive of learning performances in either an instrumental or spatial task, but the horses that crossed successfully this novel (fear-inducing) area while handled learned and memorized better an instrumental task. In Lansade and Simon (2010) and Valenchon et al. (2013a), the measure of fear varied between studies or parts of the studies (strong reactions at crossing a novel area or towards a sudden stimulus in one test; reactions over all the different temperament tests; measures could be latency to eat in a conflict of motivation test, flight distance from a sudden stimulus, or startles throughout the different tests). Désiré et al. (2002) have shown that lambs react differently to suddenness and novelty. Finally, the age and type of population may also have an influence. Published data obtained on 87 French saddlebred geldings (aged 5-23 years), living in the same conditions and subjected to different emotionality tests (Hausberger et al. 2011), were reanalyzed by examining further their responses to an instrumental task (chest opening). Results show that there is a clear correlation between the bridge test while handled and the time required to open the chest: the less fearful horses were better learners, confirming Le Scolan et al (1997)'s findings (Fig 1a). However, there was no correlation between their responses towards a novel fear-inducing object and their performances in this learning task (Fig 1b). Different emotionality traits and cognitive abilities may thus be differently interrelated. 

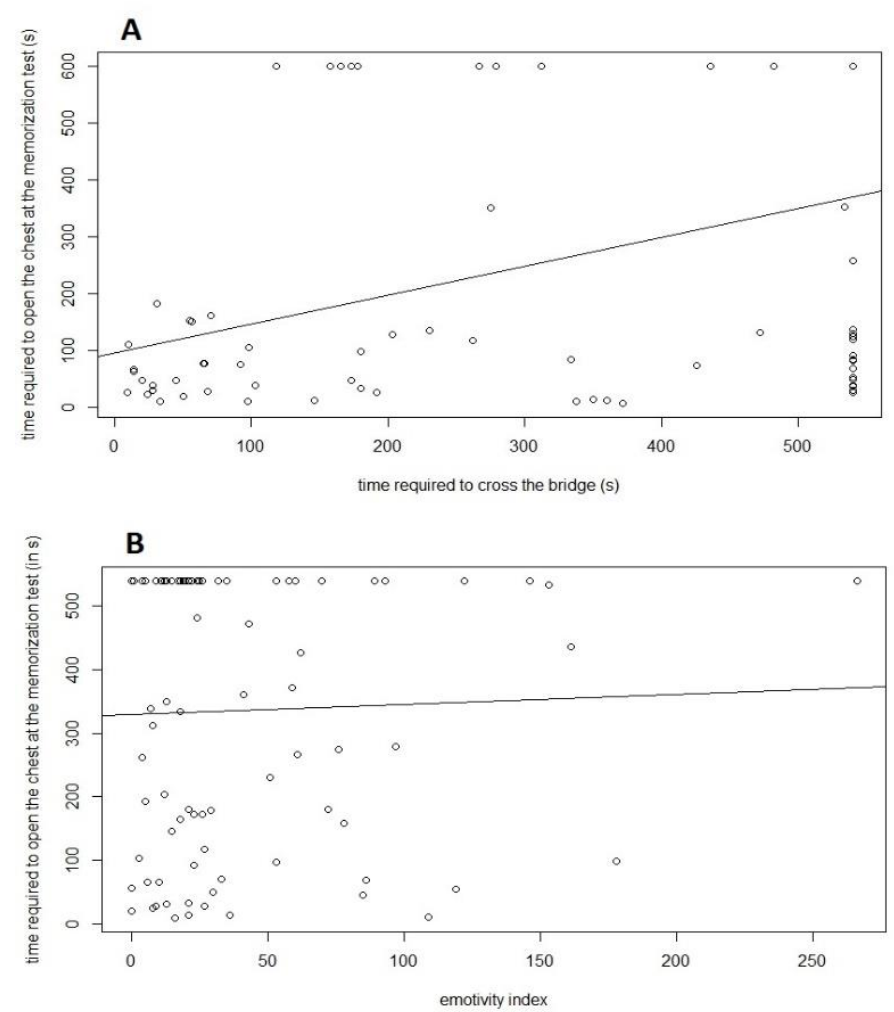

Fig. 1: a) Correlation between the success of memorization of the instrumental task (time required to open the chest in seconds) and the time required to cross the bridge during the "bridge test" (in seconds), Spearman correlation, $\mathbf{P}<\mathbf{0 . 0 0 0 1}, \mathbf{r}=\mathbf{0 . 4 0}$; b) ) Correlation between the success of memorization of the instrumental task (time required to open the chest in seconds) and the emotionality index (composite score) measured from the responses towards a novel object, Spearman correlation, $\mathrm{P}=0.69$, $\mathrm{r}=-\mathbf{0 . 0 4}$; observed in 87 French saddlebred adult sport horses (data from Hausberger et al. 2011).

On the contrary, when analyzing further data from Wolff et al. (1997) and Wolff \& Hausberger (1996)'s studies on young untrained French saddlebreds, we found that there was no correlation between a horse's reaction to the bridge and its learning performances in a chest opening or a detour task. However, the animals that were successful in both learning tasks had lower emotionality indices in the novel object test than the unsuccessful animals (chest: $\mathrm{N}_{1}=6, \mathrm{~N}_{2}=7$, $\mathrm{U}=7.5, \mathrm{p}<0.04$; detour: $\left.\mathrm{N}_{1}=10, \mathrm{~N}_{2}=13, \mathrm{U}=38, \mathrm{p}<0.05\right)$.

Therefore, different emotionality traits, as measured here through different tasks (Le Scolan et al. 1997), may each differently influence acquisition and memorization processes, but different 
populations (here young untrained versus adult trained) may show different influences of emotionality on learning and memory.

In conclusion, although there is clearly an interrelationship between emotions and learning, clarification is needed on how it works. Such considerations have applied consequences: care has to be taken to train the animals in a quiet non-stressful environment and attention certainly has to be given to individual characteristics in order to adapt the training program. Even though the most fearful animals may learn better avoidance tasks, it may induce even more fear and probably compromise the animal welfare if repeated regularly.

Indeed, individual differences may reflect differences in temperament, but also welfare conditions. Thus, animals in impoverished conditions may become more reactive in challenging situations than animals that have access to a socially and/or spatially "normal" (i.e. corresponding to the species' needs) (Rivera et al., 2002; Lesimple et al., 2011) or « enriched» environment (Lansade et al., 2014). Even depressed, and otherwise apathetic, horses may show extreme high reactions when facing a novel object in a familiar environment (Fureix et al., 2012b). Dressage horses, which experience more riding constraints and exhibit more welfare problems than horses working in other sport disciplines, show a higher emotionality in temperament tests (Hausberger et al. 2009, 2011). Horses experiencing mostly punishments may also become overreactive (McGreevy and McLean, 2005).

\section{EFFECT OF (CHRONIC) ALTERED WELFARE CONDITIONS/ STATE ON COGNITIVE ABILITIES}

Few studies have effectively dealt with this question in animals: are welfare and cognitive abilities related? The welfare issue is very important in horses. Most domestic horses live in restricted spatial (e.g. Bachmann et al. 2003), feeding (e.g. McGreevy et al., 1995), social (e.g. Visser et al., 2008) and work conditions (e.g. Lesimple et al., 2010) that may impair their well being (McGreevy et al., 1995; Lesimple et al., 2016b). This results in the emergence of abnormal behaviours (e.g. stereotypies, e.g. Mills, 2005), depression-like syndromes (Pritchard et al., 2005; Hall et al., 2008; Burn et al., 2010; Fureix et al., 2012b, 2015), back problems (Fureix et al., 2010; Jeffcott, 1979; Lesimple et al., 2016a) and abnormal postures (Fureix et 
al., 2011b; Lesimple et al., 2012a; Sénèque et al., 2019), or orientations (Hausberger et al., 2016).

\section{Causes of compromised welfare}

\section{Housing and management}

Pastured and group-housed young horses progress more quickly during training than those housed in single stalls (Rivera et al., 2002; Søndergaard and Halekoh, 2003). Lansade et al. (2014) tested the learning performances in a food-rewarded target-learning task of yearlings kept, outside training, either in "enriched" (varied diet, turned out in groups regularly, large stalls, music and objects) or in "control" conditions: both groups learned but the yearlings living otherwise in "enriched" conditions learned better than the control when there was a primary positive reinforcer associated (i.e. were more sensitive to outcome). Since the control condition corresponds to the usual impoverished management conditions of most domestic horses, these results indicate that the usual domestic situation (more than $90 \%$ of the French riding school horses are in single stalls [Lesimple et al., 2016b]) may well depress the ability of horses to assess the outcome of their actions. Boissy et al. (2007) suggest that such procedures where "environmental enrichment" consists of adding resources to an impoverished setting should be called "housing supplementation" (Benefiel et al., 2005). It would also be important to disentangle the precise aspects involved for some "enrichments" (e.g. objects, tools, toys) that may well be stressful for some horses (e.g. frustration with Edinburgh foodball, a special ball that horses have to move around or shake so that the pellets inside can fall through small holes : Goodwin et al., 2007).

\section{Animal-based indicators and effects of a compromised welfare state on cognition}

Stereotypic behaviours and other abnormal repetitive behaviours

Stereotypic behaviours are a common well known expression of altered welfare and chronic stress, reflecting inappropriate conditions of life (Mason, 1991). In horses, there are many aspects involved such as availability of roughage, group housing, weaning conditions or even riding techniques (Mills, 2005; Lesimple et al., 2016a), mostly divided into oral or locomotor stereotypies. Different authors have suggested that oral stereotypies and especially crib-biting (horse grasps a fixed object with its incisors, pull back and draws air into the cranial oesophagus 
while emitting a characteristic pharyngeal grunt: Mills, 2005) are associated with acidity in the digestive tract, due to an excess, in particular, of starch (Nicol 1999). Different types of stereotypies and abnormal repetitive behaviours can emerge according to the type of work the animals are used for (Hausberger et al., 2009). Stereotypies have been sometimes associated with high plasma endorphin levels in horses (McGreevy and Nicol, 1998; Lebelt et al., 1998) and in other species (Cronin, 1985) although large variations appear between studies. Endorphins may be involved both in terms of plasma levels, reflecting then the release of pituitary endorphin in the blood as a HPA stress response, and in the brain as high levels of endorphins (or opioids) in basal ganglia are associated with the onset and maintenance of stereotypic behaviours (Nisticò et al., 1981). Since opioids are supposed to have a general negative effect on learning (Guarna et al., 2004; Hoyamoun et al., 2003), this may explain such results. The mesoaccumbens and nigrostriatal systems are involved in stereotypies in other animals (Cabib et al., 1998). Basal ganglia seem to be involved in stereotypies of animals as well as in several motor disorders in humans (Nurnberg et al., 1997; Powell et al., 1999; Garner et al., 2003). The tics and compulsive disorders observed in the Tourette syndrome seem to be associated with learning disabilities, as a result of a dysfunction of basal ganglia (Burd et al., 1992; de la Tourette, 1899; Fattapposta et al., 2005, Leckman, 2002; Marsh et al., 2004, Singer, 2005). Basal ganglia play indeed a major role in learning, motivation, sensitivity to reward and action selection (Mason and Latham 2004; Parker et al. 2008).

Hausberger et al. (2007a) tested 77 French Saddlebred geldings in an instrumental task (chest opening) and observed that animals that had been exhibiting abnormal repetitive behaviours, e.g. repetitive tongue twisting, licking, including particular stereotypic behaviours: e.g. weaving (Mills, 2005) over two observation periods at 3-month interval were less performant in an instrumental task than animals without any repetitive abnormal behaviour. Because these horses also spent less time lying and sleeping in their stalls, the authors attributed at least partly this deficit to a potential fatigue leading to attentional deficits. No variation according to the type of abnormal behaviour could be found (Hausberger, unpubl. data). Thus, all studies (Hemmings et al., 2007; Hausberger et al., 2007a; Kirsty et al., 2015; Parker et al., 2008, 2009) until now have demonstrated learning impairments in stereotypic horses. Only one recent study (Briefer Freymond et al., 2019) seems to contradict this finding: using a reversal learning task, the authors did not find any difference in learning performance between crib-biters and nonstereotypic horses (as identified by owners). Reasons for this are unclear (type of task?, lack of identification by owners of other stereotypic disorders present in the so-called control horses?). The reason evoked by the authors, namely that the horses were stressed in previous studies 
because they were not allowed to perform their stereotypies is not valid since none of the other studies used any device to prevent horses from performing them. However, the high expression of stereotypic behaviours during the learning task in this latter study is on the other hand very intriguing, suggesting that reversal learning may be more frustrating than the tasks tested in earlier studies. Overall, most scientific evidence shows that abnormal behaviours such as stereotypies are associated with learning impairments.

Furthermore, alterations in learning processes were found in crib-biting horses in other studies although the low sample sizes sometimes hinder definitive conclusions. Crib-biters appeared to favour Stimulus-Response processes over the Response-Outcome process during task acquisition (Parker et al., 2008, 2009) and to resist more to extinction (Hemmings et al. 2007; Kirsty et al., 2015). These findings, according to the authors, reflect a tendency for automated habitual responses and are due to abnormalities in the dopamine system of the ventral and dorsolateral putamen striatum (McBride and Hemmings, 2005). As mentioned by authors (e.g. Hemmings et al., 2007), "the processes are not quite clear yet due to the many possible multimodulatory effects that dopamine systems can have within the striatum".

Vertebral disorders

Back disorders are highly common in riding horses and may, like in humans, be associated with chronic back pain (Haussler, 1996; Lesimple et al., 2016a). In humans, chronic back pain has an impact on a subset of cognitive domains including attention, learning, and memory (Mao et al., 2014). Chronic pain leads to sensory inattention and withdrawal (Eccleston and Crombez, 1999). In a study by Rochais et al. (2016), more than 100 riding school horses were, on one hand, observed in their home stall and, on the other hand, examined by trained chiropractors (for half of them) or through an electromyogram (for the other half). The time spent by horses in observation (standing quietly while monitoring the environment, head and ears mobile) was negatively correlated with the estimated degree of alteration of their back: the healthier the horses, the more calm attention they showed towards their environment. On the contrary, the most affected horses showed an attentional disengagement.

Depression-like syndrome/apathy

Different reports indicate that in clearly altered health or welfare states, horses and donkeys may seem to have "switched off" (i.e. no interest for their environment) (Ashley et al., 2005; Pritchard et al., 2005; Burn et al., 2010). This syndrome, characterized by head lowering and 
above all bouts of total immobility (fixed stare, head, ears, (Swann, 2006; Fureix et al., 2012b; Popescu and Diugan, 2013a), is also associated with abnormally low cortisol levels and anhedonia (Fureix et al., 2012b, 2015). Swann (2006), Burn et al. (2010), and Popesciu \& Diugan (2013) showed that such horses or donkeys often had injuries, skin wounds, and a poor body condition. It has been proposed that this state of apathy results from learned helplesness, when individuals have no escape from repeated aversive events (e.g. pain when ridden) (Hall et al., 2008). Such animals are non responsive to external events such as a human approach (Burn et al., 2010; Fureix et al., 2012b; Pritchard et al., 2005; Swann, 2006) and show lowered and abnormal responses to sensory stimulations such as tactile or auditory stimulations (Fureix et al., 2012b; Rochais et al., 2016b). Such lowered attention could reflect a problem of resource allocation (not enough energy for effortful cognitive processes). It may also reflect a negative emotional state that disrupts attention from external stimulations (self-centered attention).

Sensory withdrawal appears regularly in case of sickness and can also be expressed through particular orientations. Thus anaemic (haemoglobin counts lower than norm) horses tend to spend most time oriented towards a wall, away from visual stimulations and human contact (Hausberger et al., 2016). Positioning in the stall is one of the key parameters for welfare in Price et al. (2003), with more time at the front being a positive sign.

In conclusion, although studies are still scarce, alterations of welfare in horses do indeed affect the cognitive abilities of horses. Learning tasks require that arousal is moderate with intermediate HPA activation (Mendl et al., 2009). Elevated or abnormally low levels of cortisol, as observed in the highly reactive and depressed-like horses respectively, may hinder memory formation. The recent finding that chronic stress may be associated with abnormally low cortisol levels in horses (Pawluski et al., 2017) suggests that improvement of welfare conditions should be a central question for horse owners, riders and trainers, who want their horses to perform well and learn new tasks.

Moreover, the observed lower sensitivity to actions' outcomes, reduced attentional engagement, and sensory withdrawal show that the welfare state has an important impact on how horses "see the world" (Cheney and Seyfarth, 1992). One may thus expect horses with reduced interest for their environment to be less willing to interact positively with humans and learn new tasks. 


\section{WELFARE AND COGNITION INTERELATION AFFECT HOW HORSES "PERCEIVE THEIR ENVIRONMENT"}

In this section, we examine how the long term affective states modulate the valence horses will attribute to current and future events. Long term affective states are known to have an impact on cognitive processes such as attention, memory, learning, and decision (Paul et al. 2005). Positive states will bias attention and appraisal of the situation: optimistic persons tend to overevaluate ambiguous signals as positive signals (Paul et al., 2005). Cognitive bias studies where animals are trained to discriminate stimuli or locations, associated respectively with a positive or negative valence have successfully shown that gentle contact with humans (Brajon et al., 2015) and improvements of life conditions (Bateson and Matheson, 2007; Harding et al., 2004) were associated with more "optimistic" responses.

On the other hand, and as a consequence, the expectations that animals may have about their environment also reflect their internal state. The domestic or captive environment is usually highly predictible, with routine schedules for meals particularly important in determining the daily patterns of an animal's activity (e.g. Clegg et al., 2017; Lima et al., 2017; Watters, 2014). Environmental conditions, such as food availability or quality are much more predictible than they would be in natural conditions. The animals can therefore learn to associate (Pavlovian conditioning) time or signals with significant events which can be either positive or negative (Pavlov, 1927). Many species for example show anticipatory behaviours just before feeding times, which reflects their ability to "project" in the future; as is the case for any associative learning (signal or time will be followed by a consequence) (e.g. Aubé et al., 2017; Moe et al., 2006; Vinke et al., 2004). In the case of event-related anticipation, only relevant events are retrieved in the environment, according to the animal's motivation to get a specific resource (Spruijt et al., 2001). In case of time-related anticipation, the animals would rely upon the routine intervals between two occurrences (e.g. going out) that would come under one category known as interval timing, the end of one event and the beginning of the same following event being stored in the working memory (Balsam et al., 2009). Finally, anticipatory activity could depend not upon the known circadian oscillator but upon a different circadian oscillator (Storch and Weitz, 2009). Thus, anticipation of events involves learning, memory, timing and homeostatic processes (Balsam et al., 2009).

It has been proposed that anticipatory behaviours about positive events are a good welfare indicator as they reflect reward-sensitivity related to previous experiences, acquired through Pavlovian conditioning (Spruijt et al., 2001). This of course opposes to the anhedonia observed 
in some depressive syndromes (see above), although to our knowledge no specific study has tried to investigate anticipatory behaviours in otherwise apathetic animals.

\section{Long-term affective states: mood}

In a recent study, 34 horses living in restricted or more naturalistic (outdoor leisure riding) conditions were submitted to a cognitive bias test (Henry et al., 2017). They were trained to go to one or another location for the positive stimulus and to the other location for the aversive stimulus. Both populations learned the task, but when the ambiguous signal was closest ("near negative") to the aversive location, all the recreational horses went to this location, showing a positive judgement bias, whereas only 25 - $40 \%$ of the other horses did. Welfare assessments confirmed the compromised state of the horses living in restricted conditions, but also confirmed the impact of the welfare state on the animal's cognitive biases. The more pessimistic (as shown by their negative judgement bias (Harding et al., 2004)) the horses were in the test, the more they had their ears backwards while feeding (sign of discomfort and/or "bad mood") in their usual setting, and the more they expressed aggressiveness towards the experimenter during human-horse relationship tests.

Aggressiveness towards conspecifics is observed in challenging situations such as in pigs after re-housing and mixing with unfamiliar individuals (Stukenborg et al., 2011) or in absence of straw-bedding enrichment (Day et al., 2008). In horses, such predominance of aggressive behaviours was also observed in paddocks where mares were housed with high density and no food availability (Benhajali et al., 2008). Horses may also become more aggressive towards humans as a result of social isolation (Søndergaard and Halekoh, 2003). Aggressiveness towards conspecifics (Budras et al., 2001) and humans (Ashley et al., 2005; Fureix et al., 2010) is frequent when animals are in pain. Interestingly, aggressiveness appears as a general state, as riding school horses that were aggressive in the paddock were also those who threatened the experimenter in the stable (Hausberger et al., 2016). In humans, according to the cognitive neuroassociation theory, unpleasant experiences produce negative affects that stimulate "aggressive thoughts" (Berkowitz, 1993). Conversely, young horses kept in "enriched" conditions as well as sport horses benefitting from a device allowing quasicontinuous foraging developed a more friendly "attitude" towards humans (Lansade et al., 2014; Rochais et al., 2018). This is probably not just a conditioning effect as broodmares given access to continuous feeding developed more affiliative interactions with conspecifics also 
(Benhajali et al., 2009). Although of course the interactions will play a major role in the way horses perceive humans (see below), the above mentioned examples clearly indicate that the encounters have less chance to be positive if the horse is experiencing a negative affect due to its conditions of life.

\section{Anticipation of events}

Anticipatory behaviours correspond to an increase of activity (number of behavioural transitions), increased attention towards external signals, but also often include frustration behaviours, aggressions, and stereotypic behaviours (e.g. Vinke et al., 2004). One study has specifically studied anticipatory behaviours before feeding time in horses and observed, as in other species, more changes of activity, more positioning in the front part of the stall but also signs of frustration such as pawing, bar biting, threatening, yawning, tail swishing (Peters et al., 2012). This is in accordance with the general observation that prefeeding time is best for detecting stereotypic behaviours (e.g. Mills, 2005). Anticipation of meals may reflect expectations of a positive event that may clearly quickly transform into frustration. Fureix et al. (2011a) found that more than the expectation of food, the observation of neighbours getting it increases both stereotypies and yawning in adult horses: in a facility where all horses were fed simultaneously, this increase of frustration behaviours in the minutes preceding food distribution was not observed. There is a discrepancy between laboratory studies where anticipation of rewards is related to short-term responses, and field studies where rewards are anticipated early (up to 30 minutes), and discrepancy between expectancy and time of reward is extensive. Whether anticipatory behaviours can, in all cases, be considered as an indicator of positive emotions, and even more so of good welfare, is therefore an important question. In dolphins, anticipation in the usual setting reflects rather a challenged welfare (e.g. Clegg and Delfour, 2018). We believe that more thought and studies are needed before using anticipation as a reliable indicator of positive emotions (Boissy et al., 2007; Maigrot et al., 2017).

Training and work sessions can also lead to anticipation in dolphins (Clegg et al., 2017) and Clegg et al. (2008) observed an increase of weaving in horses before exercise. On the contrary, young horses appeared to be looking for the training session in Sankey et al.'s (2010b) study (see below). The type of anticipation behaviors certainly differs according to whether work or training is perceived and memorized as a positive or negative experience (i.e. association of situations (here work sessions) with positive or negative affective states, McGreevy and 
McLean, 2005). Anticipation of reward or aversive stimulus also explains the role of reinforcers in learning processes, hence training.

In Sankey et al. (2010b)'s study, anticipation of the training session and its type occurred at the third day of daily 5 minute sessions: the horses' heart rate increased before the session started when a negative but not when a positive reinforcement was used in a backing up task. Anticipation of positive reinforcement also occurs: we reanalysed the data obtained in Sankey et al. (2010b)'s study on 19 young horses by analyzing their behaviour, before the trainer entered the arena. It appeared that on the last day of training, all positively reinforced yearlings $(8 / 8)$, but only one control (1/7) were standing near the door she usually used to enter the arena, thus seeming "ready" to start training. In addition, before she entered, seven of the positively reinforced horses gazed at her at least once and five of them oriented their ears towards her, but none of the controls did (gazing: Fisher test: $\mathrm{P}=0.001$; ears orientation: Fisher test: $\mathrm{P}=0.02$ ).

In conclusion: the way horses perceive and represent their social and non-social environment is influenced by their chronic welfare state. Thus, it does influence their positive or negative perception of current events, their expectations as for the near future and their motivation for action.

\section{HOW HUMANS “USE” HORSES IMPACT THEIR WELFARE AND COGNITION}

Humans are part of the environment of the domestic horse and play a major role, indirectly through management, and directly via their actions (handling, education, training, work) from very early on (e.g. Henry et al., 2009). Their constant presence may enhance or diminish welfare according to the emotions they trigger. If humans are a source of fear, repeated encounters may well challenge the animal's welfare through repeated negative emotions (see also (Hemsworth and Coleman, 1998)).

\section{How horses perceive humans}

As indicated earlier, the prevalence of aggressive horses in domestic facilities is worrying and associated with accidents (Søndergaard and Ladewig, 2004). Fureix et al. (2009) performed a series of "classical" human-horse relationship tests (Hausberger et al., 2008) on 59 riding school horses: motionless person (MP), approach-contact (ACT), sudden approach (Sud Ap), saddle (appears suddenly with a saddle on the arm), halter fitting. Both positive (attention with forward ears, investigative behaviours) and negative (threats to bite or kick or event actual bites and 
kicks) behaviours towards the unfamiliar experimenter were recorded. It appeared that the more "invasive" the tests were, the less investigative behaviours (58\% at MP, 30\% at ACT, 12\% at Sud Ap) and the more threats (15\% MP, 32\% ACT, 51\% Sud Ap) were observed. More than $20 \%$ of the horses threatened the experimenter when she came with a saddle or tried to put the halter on. Interestingly, positive reactions at the MP were predictive of positive reactions only at the tests that were not work-related. On the contrary, negative reactions at the MP were highly predictive of difficulties to approach in the ACT and of threats at all other tests, as well as of a longer time to fit the halter.

The same horses were observed during stall cleaning by their usual caretaker: horses that threatened their caretaker had more chances to threaten the unfamiliar person during the test while those that showed investigative behaviours did so too in the tests.

This study reveals that 1) there was a clear generalization of human "representation" as a source of positive or negative emotions, 2) negative states override positive ones (see also Hemsworth and Barnett, 1987), 3) negative reactions were related to approach, and especially in association with work-related objects.

These results confirm earlier findings revealing that reactions to unfamiliar persons depend on the caretaker (Hausberger and Muller, 2002) but differ from those of Lansade \& Bouissou (2008) who found that positive reactions at the MP test were predictive of positive reactions in other tests. Interestingly, the latter study was performed on young untrained animals which may explain that they did not perceive negatively human approaches or halter fitting, while riding school horses may have associated the approach of an unfamiliar human, and still more so, its association with work-related objects, as predictive of a potentially aversive working situation (see below). This discrepancy between trained and naive horses reinforces the idea of an experienced-based memory of humans (see also dairy calves: De Passille et al.,, 1996; farm animals: Hemsworth and Barnett, 1987; pigs: Tallet et al., 2018 for other domestic species).

Findings of Baragli et al. (2009) further reinforce this idea as they show an increase of heart rate when the handler enters the area and a peak when it fits the halter in riding school horses, grazing horses that were used for sport, and feral ponies trained with a constraining approach. On the contrary no increase in heart rate was observed for feral ponies trained so as to let the individual be in control of the situation (retreat if it wishes so). 


\section{The cognitive components of the human-horse relationship}

The establishment of the human-animal interspecific relationship follows the same principles as that of intraspecific relationships: it is an emerging bond from a series of interactions (Hausberger et al., 2008; Hinde, 1979; Waiblinger et al., 2006). Interactions are short events where an individual $\mathrm{A}$ addresses an individual $\mathrm{B}$ who in turn responds, at that stage, both interlocutors do not have expectations on the other's behaviours or on the issue of the interaction. The relationship is established after a series of interactions enables each interlocutor to have expectations on the outcome of the next interaction. The valence $(+/-)$ of each interaction contributes to building a positive or negative relationship. The patterning of interactions within a relationship involves individual learning (Hinde and Stevenson-Hinde, 1968). Thus, in a recent study, d'Ingeo et al. (2019) have submitted adult horses every day for a week to two treatments with opposed valence while broadcasting a human voice, through a loudspeaker hanging at the (silent) experimenters' neck. Each horse heard a unique pair of voices, one associated with bringing palatable food, the other with bringing unpalatable food. Shortly after this training, the horses were submitted to the broadcast of the two voices, in a random order. The results show that, while the horses reacted to the sound of both voices, their responses differed, being more positive overall, even inducing in some horses an approach of the loudspeaker, for the voices that had been associated with the positive event. This is a clear demonstration of associative learning between human cues and their associated actions, which contributes to "build"a multisensory" and valenced representation of familiar humans.

This means that any human action leaves a memory that associates the event with its valence. Thus, routine procedures, such as foot care, vaccinations or transport, have an impact on the relationship built with the horse (Hausberger et al., 2008). This association can extend to human-related objects: broodmares submitted to repeated vet examinations were more reluctant to approach a vet coat put in their stall than a novel neutral object (De Boyer Des Roches et al., 2008).

The impact of necessary routine procedures such as vet care or hoof clipping can be crucial for the welfare and security of both the horse and the veterinarian are equally important (Baragli et al., 2015). Conversely, association of humans with food provisioning could explain the "taming" of young untrained horses in Sondergaard \& Halekoh (2003) study. The balance between positive and negative events, for example with regards to reinforcement during training, determines the quality of the relationship (Brajon et al., 2015a; Hemsworth and Barnett, 1987; in pigs). 
Terms like "sympathetic" methods have been used, even in scientific studies (e.g. Visser et al., 2009), for a variety of non-conventional approaches, from the join-up method, where the trainer chases the horse in a round pen until it stops and follows, to approaches where the horses can retreat and learn at their own pace. Such subjective terms should be avoided and more objective and clear terminologies, based on the real actions performed should be used. Whether or not these varied approaches are "sympathetic" from the animal's point of view is still unclear. Horses trained with the join up method did not especially follow their trainer when in pasture (Krueger, 2007) and cribbing increased after a 20 minutes forced exercise in the round pen in Whisher et al. (2011)'s study. The reaction of horses towards humans after training with a conventional versus a "sympathetic" method during a human-horse approach test did not differ statistically (Visser et al., 2009).

Finally, the negative reactions expressed by some horses for work-related objects in Fureix et al. (2009)'s study suggests that riding work may leave memories that will be positive or negative according to its quality. The type of work has an influence on the emotionality level and the emergence of stereotypies, more frequent in dressage than in jumping or eventing horses (not differing in their initial selection nor in their conditions of life) (Hausberger et al., 2009, Hausberger et al., 2011) and in horses ridden with an English rather than a Western style (Normando et al., 2011). Lesimple et al. (2016a) found that riding technique (high hands, tight reins) of beginners, influenced by their teacher pedagogy, was one of the most influential factors in the emergence of stereotypies and other abnormal repetitive behaviours in riding school horses. Work can be associated with social separation, physical constraints, pain and discomfort, contradictory orders, misuse of punishment (e.g. Hausberger et al., 2008; König Borstel et al., 2017; McGreevy and McLean, 2005). Inappropriate riding techniques may lead to chronic back disorders that remain undetected, meaning that the horse is repeatedly experiencing pain and may associate riding sessions with negative memories (Lesimple et al., 2013, Lesimple et al., 2016a). "Conflict”/stress behaviours arise that can be misinterpreted by the rider and the unescapable situation may lead the horse to learned helplessness (Hall et al., 2008).

On the other hand, horses ridden in a more relaxed way (recreational outdoor riding with long reins and low hands) are more optimistic in a judgement bias task than riding school horses ridden with tight reins and high hands (Henry et al., 2017; Lesimple et al., 2010) . 


\section{Type of training and horses' appraisal}

There has been a growing interest to investigate the processes underpinning horse, and other animals'learning and how to promote effective and "positive" training strategies.

One of the key findings is that the nature of the training experience is crucial: the use of positive or negative reinforcement (see Supp mat.) determines the nature of the human-horse relationship in the short and in the long terms (Briefer Freymond et al., 2014; Sankey et al., 2010b, Sankey et al., 2010 c). Horse trainers tend to use more negative reinforcements (McGreevy et al., 2011; Warren-Smith and McGreevy, 2008) which implies using an aversive stimulus that is ceased as soon as the horse produces the desired behaviour (Skinner, 1938). Although equally efficient in eliciting learning in most studies performed, the use of negative reinforcements is associated with increases in stress levels during training (Visser et al., 2009; Sankey et al., 2010b; Christensen, 2013; Valenchon et al., 2017). As mentioned earlier, elevations of heart rate can even be observed before the onset of training, revealing a clear anticipation of the training procedure, during which the horses' behaviour (ears backward, postures of avoidance) reflects that it is perceived as a stressful event (Sankey et al., 2010b). Skinner (1976, pp 62) even wrote that "punishment is easily confused with negative reinforcement, sometimes called "aversive control". The same stimuli are used, and negative reinforcement might be defined as "the punishment of not behaving", since if the animal does not respond appropriately, the aversive stimulation increases, although punishment is exclusively used to diminish a response (see Supp mat.).

Exclusive use of negative reinforcement does compromise the human-horse relationship and leave long term memories (Briefer Freymond et al., 2014; Sankey et al., 2010b) which means that its repeated use may compromise horse's welfare. This is still more the case when it is inappropriately used. Describing positive and negative reinforcement as merely "adding and subtracting" actions towards the horse's response (McLean and Christensen, 2017b) is not enough. Forgetting the rewarding and aversive nature associated respectively with each of them may contribute further to the lack of understanding of the aversive nature of negative reinforcement. Beyond the fact that this would be unique to horse training, it may therefore not be such a good idea. Positive reinforcement training (PRT) has been proposed as a way to promote improvements in the management and welfare of zoo and domestic animals (e.g. antelopes: Grandin et al., 1996; rhinoceros: Holden et al., 2006). It has been shown to improve the welfare of laboratory animals (mice: Cloutier and Newberry, 2008; primates: McKinley et al., 2003; Reinhardt, 2003) and to induce positive emotions in dogs and wolves (Vasconcellos 
et al., 2016). Several authors have found that horses trained or rehabilitated using positive reinforcement, which strengthens a behavioural response by delivering a pleasant, appetitive stimulus upon its performance, tend to learn faster, show greater motivation to engage in training, display more exploratory, affiliative behaviours and less problematic defence behaviours during training (e.g. biting or kicking) and have better memory (Ferguson and Rosales-Ruiz, 2001; Hockenhull and Creighton, 2013; Innes and McBride, 2008; McCall, 2007; Sankey et al., 2010b, c; Slater and Dymond, 2011; Warren-Smith and McGreevy, 2008). PR horses tend to develop a more positive attitude towards their trainer (Sankey et al., 2010c) that goes beyond training and the individual trainer and remains over a long term period (Sankey et al., 2010b, c). In the study by Briefer Freymond et al. (2014), during training, horses trained with positive reinforcement showed again more positive behaviours in general (e.g. ears forward) and towards the trainer (comes closer) than those trained by negative reinforcement (e.g. ears backwards). Therefore, when at the end of the training, the negatively reinforced horses showed more positive biases in a judgment test, the authors concluded that this optimistic bias may have been triggered by release of the negative state experienced during treatment. The only alternative possibility would be that the procedure did not really allow to assess the horses' affective state, and other cognitive bias studies, using slightly different procedures, in horses were good predictors of their welfare state (e.g. Henry et al., 2017). Moreover, not all intended reinforcements are equal. Most studies have successfully used food rewards as a positive reinforcement, but professionals and amateurs often choose tactile contact over food: they pat, stroke or scratch the withers in an attempt to mimic horse-horse interactions (Feh and de Mazières, 1993). Naïve horses do not necessarily perceive stroking as a positive stimulation and may even avoid it (Henry et al., 2006), but scratching at withers, observed in social interactions, was a likely candidate for being a potential primary reinforcer, especially as it is associated with a lowering of heart rate in human-horse interactions (Feh and de Mazierès, 1993). Studies performed to test this hypothesis by using scratching the withers as a positive reinforcement instead of a food reward have however not shown any increase in performance or motivation nor the improvement of the human-horse relationship observed with food reinforcement (Ellis and Greening, 2016; Rochais et al., 2014; Sankey et al., 2010a). Duration of reinforcements (made identical in Sankey et al's 2010a study) and types of actions (e.g. no movement towards the horse's head in any case) could not explain these differences between tactile versus food reinforcement. Even in Watson \& Mc Donnell (2018)'s study, which aimed to improve comfort and compliance of horses during mildly aversive health care procedures, food reinforcement appeared as clearly the most efficient means: even though rubbing the eyes 
or scratching the withers also lowered the avoidance response, they did it twice less than food. Only food consistently increased median relaxation and movement rating score.

Heart rate changes are not reliable predictors of the emotional valence of a situation as positive emotions can be associated with either increased or decreased heart rates (Peters et al., 2012). It is possible that longer tactile stimulations may improve the effect of the procedure. However this effect remained low in Watson \& Mc Donnell (2018)'s study despite 3 minutes scratching (instead of a few seconds in the other above mentioned studies). Therefore, a short duration of the stimulation is not a factor explaining the lack of effect of this stimulation. This means that this procedure is less motivating for the horse and would be less practical to use in a training context, where 3 minutes or more is quite a long time for a reinforcement whereas one small food pellet is efficient in a few seconds. On the other hand, the use of PRT has enabled Sankey et al. (2010c) to train the horses to accept a series of routine procedures, such as lifting the feet, putting the surcingle, to more invasive procedures, such as applying a spray and a thermometer. Mc Donnell (2000) was very successful with a procedure that, through positive reinforcement (mostly food), allowed horses to accept mild vet procedures.

Moreover, young naïve horses clearly differed in their reaction to scratching, thus in their appraisal of human tactile contact (Rochais et al., 2014). As (human) primates that are very sensitive to tactile stimulation (Barnard and Brazelton, 1990; Harlow et al., 1965; Harlow and Suomi, 1974), we often assume that stroking companion animals is also positive for them. This is probably the case in altricial species where siblings have close contact, also with their mothers, and most cats or dogs seem to intrinsically appreciate human contact (Lowe and Bradshaw, 2001). On the other hand, more precocial species like ungulates have generally only one young that receives little physical contact, apart from the very early licking at birth and later direct tactile social interactions, whose frequency remains low (Gubernick and Klopfer, 2013). Thus, in cattle, Boivin et al. (1998), Jago et al. (1999), and Pajor et al. (2003) suggested that gentling was not necessarily rewarding for animals, whereas Pajor et al. (2000) even found some evidence that cows find brushing to be aversive and Anderson et al. (2002) that farm mammals in petting zoos may show avoidance of contact with humans. Foals can build a better bonding with humans using indirect actions where the foal can be the "actor" of the relationship, i.e. is initiating the interaction, than when direct handling actions are used (Henry et al., 2006). This illustrates how species-specific as well as individual differences influence animals' appraisal of situations. In Rochais et al. (2014)'s study, some yearlings appeared to appreciate withers' scratching while others clearly showed reluctance, independently of their early rearing 
condition (domestic or naturalistic conditions). However, only 4 of them learned the task and their attention to the task remained lower than that of the PR (food reinforced) horses (Sankey et al., 2010a). Tactile stimulations, like vocal stimulations, may become useful secondary reinforcements through an association with food rewards for example (see Supp mat.). The choice of appropriate (from the animal's point of view) rewards is crucial for PRT to be effective (Staddon, 1983).

According to Schmidt et al. (2010), one of the most stressful event in the riding horse's life is being mounted for the first time. In order to see whether this horse's appreciation could be improved, the 23 positively trained yearlings used by Sankey et al. (2010c) were further trained ( 5 min daily training to remain immobile on order and accept procedures with $(\mathrm{PR}, \mathrm{N}=11)$ or without $(\mathrm{C}, \mathrm{N}=12)$ a food reward when the horse was successful), when 3 to 4 years of age, to accept saddling, mounting, and riding. First, each horse had to stand still while the handler fitted a saddle pad and a saddle on its back and then while the handler mounted and lay across the saddle on the horse's back. Results of the experimental first part revealed that after only 10 sessions (i.e. 50 minutes of training), almost all PR horses stood still (without being held) throughout saddling and mounting of a handler across the saddle for at least $10 \mathrm{sec}$., whereas only one of the control horses did so within the allocated time $\left(\mathrm{N}_{\mathrm{PR}}=10 / 11, \mathrm{~N}_{\mathrm{C}}=1 / 12\right.$, Fisher's exact test, $\mathrm{P}<0.001$ ). Then, amongst these 23 horses, eight geldings (4PR and $4 \mathrm{C}$ ) were entrusted to the French military school of equitation (EME) in Fontainebleau, to take part in their usual young horses saddling and mounting scheme. Staff at the EME was naïve regarding the horses' training history and were told to proceed « as usual ». Videorecordings of the training sessions allowed later performance and behavioural analysis. The usual young horses training scheme included haltering and saddling, lunging, backing and riding at the three gaits. Three members of staff, depending on their availability, performed training. No food reward was used but trainers used verbal praise (e.g. "yes", "good”) and reprimands (e.g. "no!") as well as some negative reinforcement (e.g. during lunging sessions). The verbal signals had never been asociated with food or punishment and may have remained meaningless to the horses ( Heleski et al., 2015; McLean and McGreevy, 2010). Results of the second part revealed that the geldings that had originally been trained with a food reward (PR) required fewer training sessions than the controls to complete the various stages of the young horses' training scheme (Fig. 2). Overall, PR horses required an average of $5.75 \pm 0.48$ training sessions to be ridden outdoors, while controls required $7.75 \pm 0.63$ sessions to do so (Fig. 2). Moreover, none of the PR horses displayed defence behaviours towards the trainers, while three of the four 
controls did so at least once during training (rearing, bucking, kicking). Thus, despite of this later use of the same NR procedure, the young horses initially trained with PR remained more motivated in training and positive towards humans. Modalities of initial training may influence greatly subsequent training at later stages.

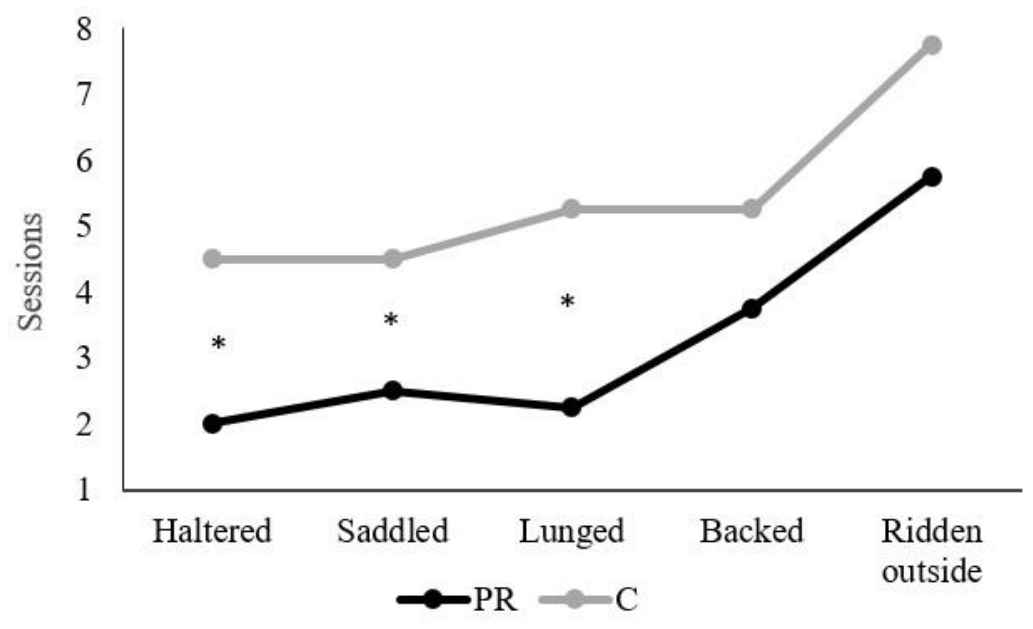

Fig. 2 : Number of training sessions required to successfully perform the steps included in the young horses training scheme, i.e. being haltered, saddled, lunged and mounted outdoors for horses that had previously undergone initial ground training with positive reinforcement $(P R)$ or no reinforcement $(C)$ (Mann-Whitney U-test: $P \leq 0.05$ ) (see also Sankey et al., 2010c).

In conclusion, horses can be efficiently trained using rewarding methods, as used with diverse species (see above) such as captive marine mammals (Brando et al., 2017; Mellen and Ellis, 1996; Ramirez, 2012) and dogs (Hiby et al., 2004), which also reinforces horse welfare and human safety. However, whatever the reinforcement, the respect of learning principles is a prerequisite to avoid improper learning (lower learning performances and undesired learned associations) and the development of undesirable behaviours. The challenge of using only positive reinforcement especially in a riding context (Brubaker and Udell, 2016) may be easily overcome by establishing secondary reinforcements (e.g. verbal praise) during the ground training preceding riding training. "Blended" (Warren-Smith and McGreevy, 2007) or combined (McLean and Christensen, 2017a) approaches where negative reinforcement is followed by positive reinforcements may also be used. In any case, the benefits of positive 
reinforcement initial training persist, even when other techniques are later used in further training or riding (see above). According to Hanggi \& Ingersoll (2009): "when what is first learned is a positive experience, subsequent learning and human-horse interactions are facilitated". These conclusions could help bridge the gap between empirical findings and applied practices. The fact that their own actions have a rewarding effect may also trigger further their well-being. It would be interesting to see whether PRT may stimulate horses' immune system as observed in pigs (Ernst et al., 2005). The authors suggest that enhanced attention and cognitive activity is source of more positive emotional states. The question of the type of reinforcement to enhance well-being and learning is not proper to animal training: in humans too, it has been suggested that the systematic use of positive reinforcement in classrooms not only increased the children cognitive performance but also improved their behaviour at school (Chance, 1992).

\section{ATTENTION: A CORE ASPECT OF THE RELATIONSHIP BETWEEN COGNITION, POSITIVE RELATIONSHIPS AND WELFARE STATE?}

Attention is an integral part of all cognitive processes as it modulates perception (e.g. Cousillas et al., 2008), learning and memory (Rochais et al., 2014, 2017b). Sustained attention has been proposed as the main process linking working memory and learning abilities (Cowan, 1997).

It is also strongly affected in the case of an altered welfare: stereotypic horses may focus on their stereotypy, depressed and anaemic (i.e. low hemoglobin level in blood) horses display no attention towards external stimulations and horses with back disorders show a lesser attentional engagement.

\section{Positive training procedure may enhance horses' attention}

The question also arises of whether training could be used to promote attention (Rochais et al., 2014).

We (S.B., blind to treatment) reanalyzed data issued from Sankey et al. (2010c)'s study on 15 horses $\left(\mathrm{N}_{\mathrm{PR}}=8\right.$ : Positive Reinforcement, $\mathrm{N}_{\mathrm{C}}=7$ controls, no reinforcement $)$ which had been trained to stand still for up to $30 \mathrm{sec}$ in response to a vocal command (see above) with a focus on their attentional behaviours: ear posture and orientation (auditory attention), gaze direction and duration (visual attention), head and neck orientation (monitoring behaviour), time in 
contact with the trainer (investigative behaviours including sniffing, nibbling and licking) and location in the training arena. The results revealed that from the first day on, PR horses paid globally more attention to the trainer. Indeed, their auditory attention was oriented towards the trainer for longer since they spent $4.5 \pm 0.4 \mathrm{sec}$ with at least one ear oriented towards the trainer compared to $2.3 \pm 0.3 \mathrm{sec}$ for $\mathrm{C}$ horses (Mann-Whitney $\mathrm{U}$ test: $\mathrm{U}=33, \mathrm{P}=0.009$ ). They also spent more time monitoring and gazing at the trainer than $\mathrm{C}$ horses (Fig. 3). In contrast, $\mathrm{C}$ horses spent longer with their neck turned away from the trainer $\left(\overline{\mathrm{X}}_{\mathrm{C}} \pm \mathrm{SE}=0.4 \pm 0.3 \mathrm{~s}, \overline{\mathrm{X}}_{\mathrm{PR}} \pm \mathrm{SE}=0.05\right.$ $\pm 0.05 \mathrm{~s}$, Mann-Whitney $\mathrm{U}$ test: $\mathrm{U}=71, \mathrm{P}=0.05)$, gazing at the non-human environment $\left(\overline{\mathrm{X}}_{\mathrm{C}} \pm\right.$ $\mathrm{SE}=6.3 \pm 1.1 \mathrm{~s}, \overline{\mathrm{X}}_{\mathrm{PR}} \pm \mathrm{SE}=4.6 \pm 1.1 \mathrm{~s}$, Mann-Whitney $\mathrm{U}$ test: $\left.\mathrm{U}=75, \mathrm{P}=0.03\right)$. The attention of the PR horses increased over the 5 days of training: duration of monitoring and gazes towards the trainer increased for PR horses during training whereas it did not change for C horses (Fig. 3). PR horses also spent more and more time investigating the trainer (Friedman test, $\mathrm{N}=8$, df $=4$, friedman chi-squared $=17.2, \mathrm{P}=0.002)$. For instance, while they nibbled the trainer for 1.6 $\pm 1.1 \mathrm{~s}$ on the first day, they spent $15.5 \pm 6.6 \mathrm{~s}$ performing this behaviour on the last training day (Wilcoxon signed-rank test: $\mathrm{T}_{(\mathrm{NPR}=8)}=1, \mathrm{P}=0.01$ ). On the last day $\mathrm{PR}$ horses showed signs of positive anticipation: they seemed eager to start training (see Anticipation of events: standing in front of the door to the arena, gazing at trainer at her arrival). 

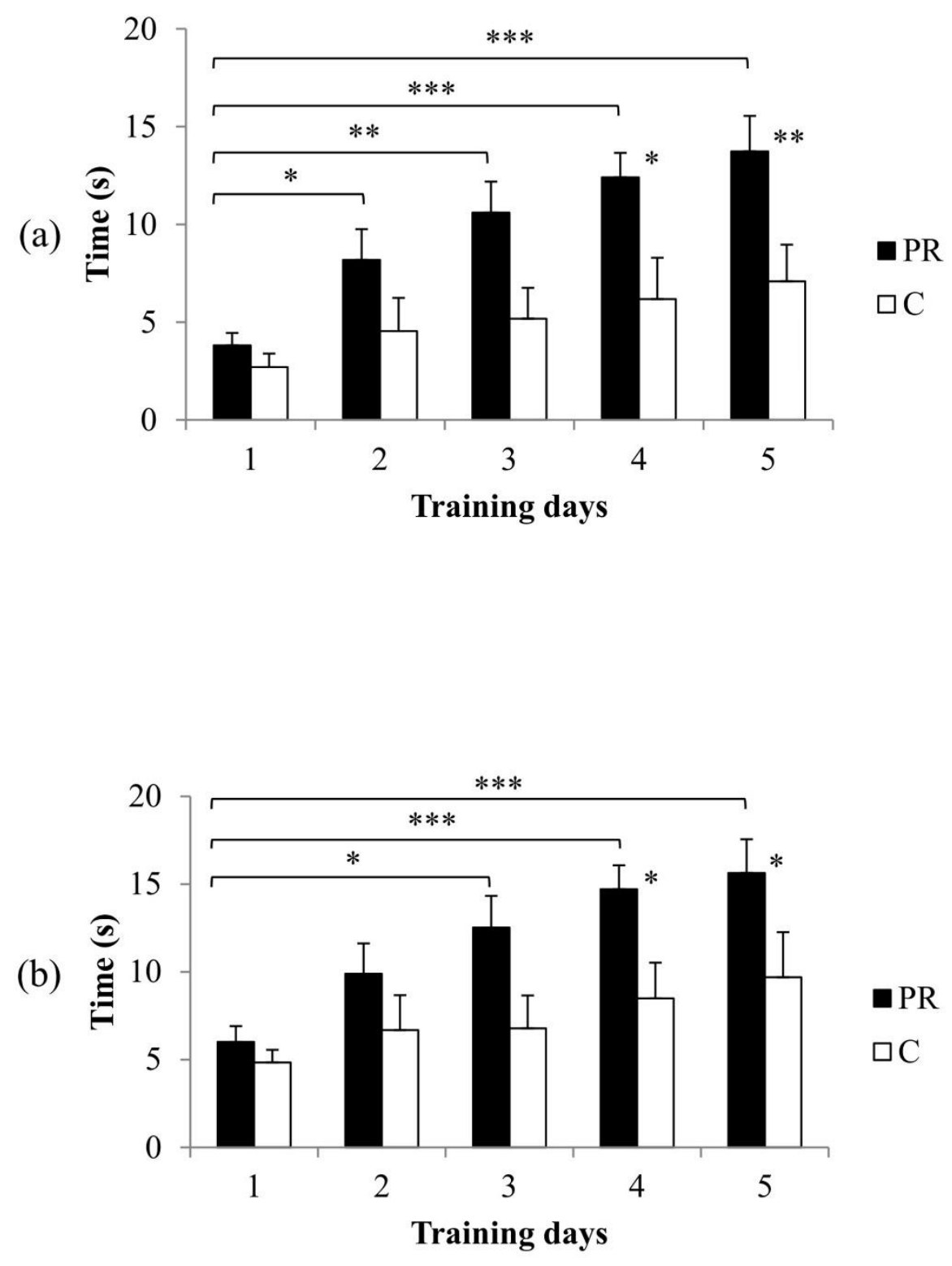

Fig. 3: Average time (seconds $\pm \mathrm{SE}$ ) spent (a) monitoring and (b) gazing at the trainer by horses from Positive Reinforcement $(P R, N=8$, Friedman test $P<0.05)$ and Control $(C$, $\mathrm{N}=7$, Friedman test $\mathrm{P}<\mathbf{0 . 0 5}$ ) treatments during the trials on the five training days (from data of Sankey et al., 2010c). Differences between groups are significant on days 4 and 5 (Mann-Whitney U-test $P<\mathbf{0 . 0 5}$ ).

Thus, it appears that positive reinforcement encourages horses to direct and maintain their attention on the trainer and his/her requests. According to Krapp (1999), a high level of motivation (here for the food reward) automatically leads to a high level of attention and fosters the readiness of an individual to become involved with the relevant information, raising the 
probability of successful learning. However, the pattern relating attention and learning may be complex, for there seems to be an optimal level of attention in order to facilitate learning, whereas too little or too much attention could, on the contrary, hamper performance (Rochais et al., 2014).

Could human attention reward the animal and be a source of positive emotions?

Horses are highly sensitive to humans' attentional states (e.g. Krueger et al., 2011). Their obedience may differ according to whether the handler is looking at them or looks distracted. Surprisingly, horses are able to detect a gaze that fixates above their head. Similarly they would detect when the person turns her/his back, but only if the trainer is not a familiar person (Sankey et al., 2011a).

One intriguing result in Sankey et al.'s studies was the finding that control (no reward) horses could slightly improve their performance despite of the absence of reinforcement. One hypothesis would be that human attention per se may act as a reinforcer, although clearly of lower interest for the horse than food rewards. A recent study by Nagasawa et al. (2015) has shown that ocytocin levels increased in dog owners when their dog gazes at them. Maybe such an increase occurs also in dogs or horses when their owner looks at them which would then constitute a reward. Although speculative, this view could lead to interesting further studies.

In conclusion, field studies are still scarce and the development of new tools for measuring attention or distractibility in simple or automated versions of attention tests (Rochais et al. 2017 b, a) should give new insights into attention and welfare issues. Measuring human attention during interactions and its consequences is another possible promising research line.

\section{ASSESSING COGNITIVE PROCESSES TO PROMOTE WELFARE AND POSITIVE} EMOTIONS: Choice and conditioning procedures

Approaches to welfare include also preference and motivation tests (Kirkden and Pajor, 2006). Two types of tests have been developed: choice tests and operant tests. Choice tests have for example shown that horses prefer a straw-bedded stall to a shavings bedding (Mills, 2000). Choice tests have to be used with care as animals may mark a preference for a resource that may well not be good for their health on the long term (van Rooijen, 1982). 
Operant tests have been successfully used in horses (Gabor and Gerken, 2012) and have confirmed that horses are motivated and ready to make efforts to obtain social contact (Søndergaard et al., 2011) and are more motivated to go to a paddock where there is food and ideally social contact over going to an empty paddock and still more so to a treadmill or a single stall (Lee et al., 2011).

A more sophisticated but promising approach has consisted to train horses to associate symbols with outcomes, in the present case putting a rug on or off their back (Mejdell et al., 2016). After a training procedure, horses were offered to push one of the symbols (on/off/no change) and were rewarded whatever their response. The results show that horses adapted their responses to the actual weather conditions, more of them asking for a rug on when the weather was relatively cold with continuous rain. High individual variations showed that management must be based on the observation of animals and reminds us of the importance of animal-based criteria.

In conclusion, the use of the cognitive particularities of the species may help finding ways to assess further the impact of human management and training practices on welfare. Preference tests may allow animals to express their own priorities and give a most direct insight into what is important to them. Being able to understand animals' preference constitutes therefore a direct way to assess the animal's subjective perception of its living conditions. Further studies are needed at this stage.

\section{COGNITION, WELFARE AND BRAIN PROCESSES: CONCLUSION AND PERSPECTIVES}

This whole review on horse cognition and learning and their interrelationship clearly demonstrates that horses constitute a unique animal model to explore the impact of emotions and (chronic) welfare on the daily cognitive investment on learning, and work (Fig. 4). There is a circularity as welfare state interferes with training and work, while on the other hand welfare is also affected by work. 


\section{Affective states}

Positive if :

$\checkmark$ Good quality of human-horse relationship at work (use of positive reinforcement, appropriate use of learning principles, appropriate riding techniques, human attention during training)

$\checkmark$ Environmental factors (appropriate housing, feeding, etc... )

$\checkmark$ Social factors (presence of social partners, etc.)

$\checkmark$ Individual factors (good health, behavioural needs fullfilled, et.c)

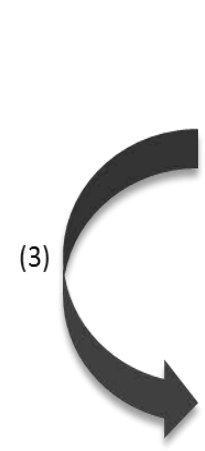

(2)<smiles>c1ccccc1</smiles>

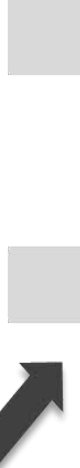

Horses' individual factors

(other than welfare state)

$\checkmark$ Genetic and breed

$\checkmark$ Temperament

$\checkmark$ Age

$\checkmark$ Past experience

(1)

\section{(1)}


Laterality is the systematic preference for the use of one side of the body over the other to realize motor or perceptual tasks involving paired limb or perceptual organs (Andrew and Rogers, 2002). In other words, laterality manifests both on the motor (e.g. hands, feet) as well as the perceptual (eyes, ears, nostrils) level. Such behavioral laterality emerges from hemispheric lateralization, i.e., the left and right cerebral hemispheres are specialized in controlling distinct neural functions or cognitive processes. Since the late nineteenth century, hemispheric specialization was believed to be a human specificity, but studies over the last 30 years have provided increasing evidence for lateralization in nonhuman mammals, including birds (e.g. Symes and Perrin, 2003) and even lower vertebrates (Rogers and Andrew, 2002). Hemispheric specialization is assumed to confer advantage to the functioning of the brain. Among other advantages, cerebral lateralization can enhance neural capacity by allowing parallel and separate processing in the hemispheres: thus, in lateralized individuals, several cognitive tasks that demand the simultaneous but different use of both hemispheres can be performed more efficiently (Rogers and Andrew, 2002). More recent studies in animals converge on the conclusion that stimuli, and in particular visual and auditory stimuli, with different emotional valences induce different lateralized responses. For example, positive emotional stimuli would be preferentially processed by the left hemisphere, while the right hemisphere would be specialized for the processing of negative emotions (Davidson, 1992).

Like most other species investigated, horses show a lateralization of perception that reflects its attentional and emotional state. As in other mammals, horses tend to process fear, novel or agonistic signals in the right hemisphere (e.g. by attending the stimulus with the left eye) (Austin and Rogers, 2014; De Boyer des Roches et al., 2008; Larose et al., 2006). Indicators of lateralization could therefore help identifying the impact of practices (Leliveld et al., 2013; Rogers, 2010).

Thus, while young naïve horses are reluctant to be approached and touched on the left side, animals trained with PRT, accepted a contact whatever the side and location (Sankey et al., 2011b). Ponies trained with negative reinforcement tended to turn the head so as to look at the trainer with their left eye while no such bias could be observed for those trained with positive reinforcement (Sankey et al., 2010b).

Only one study indicates that horses prefer to look at their trainer with the left eye (Farmer et al., 2010) generally associated with a negatively connoted situation (Austin and Rogers, 2014; Larose et al., 2006). However, although the authors consider that the trainers were positively connoted, ensuring the care and feeding of the horses, they were training the horses through a 
join up technique which, as mentioned earlier, does not seem to favour the relationship, and may even be associated with an increase of undesirable behaviors (Whisher et al., 2011).

More recently, it was shown that this overall lateralization pattern applies also to human acoustic cues: horses orient more their left side towards a loudspeaker broadcasting voices associated previously with positive events than for voices associated with frustrating events (d'Ingeo et al., 2019). Lateralization biases may thus well help us identify desirable and less desirable (from the horse's point of view) procedures to train and handle the horses. It may be the quality of work rather than work itself that may impact laterality.

\section{Promising methodological tools}

Telemetric portable EEG devices are promising tools for assessing cognitive processes during different tasks in humans (e.g. Onton et al., 2005; Rihs et al., 2007) but also in animals like horses (Cousillas et al., 2017) or rats (Jones and Wilson, 2005). A recent study conducted in horses succeeded in highlighting particular EEG activation according to the individuals' attentional level. Indeed, visual attention towards a novel but non frightening visual stimulus was associated with an increase of gamma activity in the right hemisphere while "inattention" was associated with more alpha and beta waves in the left hemisphere (Rochais et al., 2018b). In the same line, more gamma activity was observed while horses were aroused by hearing a human voice previously associated with positive experiences (d'Ingeo et al., 2019).

These results are of high interest since numerous studies linked individuals' attentional characteristics to their welfare assessment. We already know that a loss of interest in the environment and apathy are behavioural symptoms of depression in humans (American Psychiatric Association, APA 2013) and apathetic profiles are regularly described for horses (e.g. Burn et al., 2010; Fureix et al., 2012b; Hall et al., 2008; Popescu and Diugan, 2013b; Pritchard et al., 2005) and other domestic (Beerda et al., 1999; Broom, 1986; Fordham et al., 1991; Jensen et al., 1996), laboratory (e.g. Pais-Vieira et al., 2009) or captive (e.g. Camus et al., 2013) animals (review in Fureix and Meagher 2015). In horses, studies demonstrated that a decrease of attentional engagement with the environment (Rochais et al., 2016a) and less interest in environmental stimuli (Fureix et al., 2012b; Rochais et al., 2016b) was observed in animals in a poor welfare state. Thus, combining EEG with attentional measures could be an interesting base of welfare assessment in horses and more broadly in different animal species. 


\section{The cognitive brain in domestic animals: progressive or regressive evolution?}

Most studies interpret the capacity of domestic animals of interpreting human signals as the testimony for high cognitive abilities. Whether the domestication process or experience with humans (or both) are involved, these processes are viewed as a progress. However, Röhrs \& Ehringer (1993) indicate that domestication is associated with a reduction of the brain areas (cortex, striatum) that are important for cognitive processing, which for them corresponds to a « regressive evolution ». Comparing the cephalisation of different domestic species with that of their wild counterpart, they conclude that domestic dogs have lost $30 \%$ compared to wild canids and lamas 17\% compared to guanacos. Przewalski horses have the highest cephalisation grade amongst the animals they have investigated. A comparison with the cranial capacity and the basilar length revealed that domestic horses have a reduction of $14 \%$ compared to free living Przewalski horses. Interestingly, they did not find any difference between domestic horses and zoo Przewalski horses, whether in cranial capacity, or ratio brain/body weights. They concluded that zoo animals may have been crossed with domestic horses.

These observations are really intriguing, and since hybridization is frequent when a wild species becomes rare, it is probable that the free living animals may also have had crossings with domestic animals. However, the authors did not compare their data with those of feral or domestic horses living in naturalistic conditions. Rather than being the result of human actions on evolution through selection, could it be that the mostly impoverished environment provided by captive and domestic situations degrades cognition?

The finding that horses and dogs that focus on humans while having to solve a task (and thus succeeding less) is in this sense intriguing (Lesimple et al., 2012b; Topál et al., 1997). In both cases, the animals seem to expect humans to solve the problem for them. Gardner (1933) observed the same phenomenon in the military but not farm or draught horses. In most cases, animals rely upon human actions for their feeding schedule for example.

The fact that captive/domestic animals "face a schedule that is usually rigid and temporally regular with reduced choice and controllability" may constitute an "under or over" challenge (Vasconcellos et al., 2016) for cognition.

Novel behaviours increase with the complexity of the environment (Dukas, 2004) and frequent and unpredictable environmental changes may select for increased cognitive abilities, through repeated neural stimulations resulting in faster and better learning, as shown in cichlid fishes (Kotrschal and Taborsky, 2010). 
The barren and boring environments offered to captive/domestic animals lead to reduced attention and arousal at the least, while, as mentioned earlier, attention is a core issue of the interrelationship between cognition and welfare. According to Vasconcellos et al. (2016), the sensitivity to human signals could merely reflect ancestral abilities for intraspecific cooperation. The housing and training conditions offered to domestic animals may loosen their interest to actively take part. One early handling procedure at birth can teach foals that their attempts to escape are useless, as shown by their reduced mobility when facing a stressor at later ages (Durier et al., 2012). Yearlings kept in an impoverished environment learn less well than their counterparts living in a more diversified and complex environment (Søndergaard and Ladewig, 2004; Lansade et al., 2014).

Little emphasis is given yet to the type of population being investigated when cognitive capacities are tested. Life conditions at least may influence attentional processes, emotional states and behavioural flexibility. Future studies should look more thoroughly at the importance of behavioural flexibility and the potential triggering effect of changing, complex or varied environments of life and development. Would feral horses learn better complex problem solving and less well human-related tasks?

This review has largely demonstrated that welfare and cognition are clearly interrelated and that a compromised welfare leads to poorer cognitive performances and negative cognitive biases. However, the number of studies dealing with this question in animals is still low and there is a large place for future studies on this complex issue of welfare and cognition. Lines of thoughts would be comparing further animals living in different conditions and with different life histories, disentangling the role of domestication versus conditions of life in promoting or degrading cognition and looking further at the seemingly important relationship between attentional engagement and well-being.

Finally, these issues do also concern human beings since conditions of life, in terms of environmental complexity, type of work, positive or negative teaching strategies, possibilities of action and hence welfare state also modulate individual cognitive skills. Animals give the opportunity to have an integrative view that shows that the mutual relationship between cognition and welfare is well conserved along evolution and is an essential part of cognitive studies. 


\section{AUTHORS CONTRIBUTION}

MH and SH designed the manuscript, SB, CS, CL \& MS reanalysed data when appropriate, all authors contributed to the manuscript.

\section{CONFLICT OF INTEREST}

The authors declare that the research was conducted in the absence of any commercial or financial relationships that could be construed as a potential conflict of interest.

\section{ACKNOWLEDGEMENTS}

A large part of this review is based on the PhD theses of C. Sankey, C. Rochais, M. Stomp who benefitted from funding from IFCE (Institut Français du Cheval et de l'Equitation), the French Ministry of Research, the Région Bretagne and le Fonds l'Eperon. Their studies were funded by IFCE and la Caisse Centrale de la Mutualité Agricole. We are thankful to A. Lazou for his great help with the literature, to C. Fureix and C. Lesimple for useful discussions on this topic and to A. Wolff and C. Muller for their MS thesis, and E. Gautier for his DVM thesis. We are most grateful to Dr C. Symes as well as Dr K. Collier for improving the English.

\section{REFERENCES}

Ahrendt L.P., Christensen J.W., Ladewig J. (2012) The ability of horses to learn an instrumental task through social observation. Appl Anim Behav Sci 139:105-113. doi: 10.1016/J.APPLANIM.2012.03.004.

Alcaro, A., Panksepp, J., 2011. The SEEKING mind: Primal neuro-affective substrates for appetitive incentive states and their pathological dynamics in addictions and depression. Neuroscience and Biobehavioral Reviews, 35, 1805-1820. Doi: 10.1016/j.neubiorev.2011.03.002.

American Psychiatric Association, 2013. Diagnostic and Statistical Manual of Mental Disorders, in: 5th Ed. American Psychiatric Association. Arlington, VA.

Anderson, U.S., Benne, M., Bloomsmith, M.A., Maple, T.L., 2002. Retreat Space and Human Visitor Density Moderate Undesirable Behavior in Petting Zoo Animals. J. Appl. Anim.Welf. Sci. 5, 125-137. https://doi.org/10.1207/S15327604JAWS0502_03

Andrew, R., Rogers, L., 2002. The nature of lateralization in tetrapods, in: Comparative Vertebrate Lateralization. pp. 94-127.

Andrieu, J., Henry, S., Hausberger, M., Thierry, B., 2016. Informed horses are influential in group movements, but they may avoid leading. Anim. Cogn. 19, 451-458.

Ashley, F.H., Waterman-Pearson, A.E., Whay, H.R., 2005. Behavioural assessment of pain in 
horses and donkeys: application to clinical practice and future studies. Equine Vet. J. 37,565-575. https://doi.org/10.2746/042516405775314826

Asok, A., Kandel, E.R., Rayman, J.B., 2019. The neurobiology of fear generalization. Front. in Behav. Sci., 12, 329. doi: 10.3389/inban.2018.00329

Aubé, L., Fatnassi, M., Monaco, D., Khorchani, T., Lacalandra, G.M., Hammadi, M., Padalino, B., 2017. Daily rhythms of behavioral and hormonal patterns in male dromedary camels housed in boxes. PeerJ 5, e3074. https://doi.org/10.7717/peerj.3074

Aureli, F., de Waal, F.B.M., 2000. Natural conflict resolution. University of California Press.

Austin, N.P., Rogers, L.J., 2014. Lateralization of agonistic and vigilance responses in Przewalski horses (Equus przewalskii). Appl. Anim. Behav. Sci. 151, 43-50. https://doi.org/10.1016/J.APPLANIM.2013.11.011

Bachmann, I., Audig, L., Stauffacher, M., 2003. Risk factors associated with behavioural disorders of crib-biting, weaving and box-walking in Swiss horses. Equine Vet. J. 35, 158-163. https://doi.org/10.2746/042516403776114216

Bagshaw, C.S., Ralston, S.L., Fisher, H., 1994. Behavioral and physiological effect of orally administered tryptophan on horses subjected to acute isolation stress. Appl. Anim. Behav. Sci. 40, 1-12.

Baker, A.E.M., Crawford, B.H., 1986. Observational learning in horses. Appl. Anim. Behav. Sci. 15, 7-13. https://doi.org/10.1016/0168-1591(86)90017-1

Balsam, P., Sanchez-Castillo, H., Taylor, K., Van Volkinburg, H., Ward, R.D., 2009. Timing and anticipation: conceptual and methodological approaches. Eur. J. Neurosci. 30, 174955. https://doi.org/10.1111/j.1460-9568.2009.06967.x

Bantick, S.J., Wise, R.G., Ploghaus, A., Clare, S., Smith, S.M., Tracey, I., 2002. Imaging how attention modulates pain in humans using functional MRI. Brain 125, 310-319, https://doi.org/10.1093/brain/awf022

Baragli, P., Demuru, E., Scopa, C., Palagi, E., 2017a. Are horses capable of mirror selfrecognition? A pilot study. PLoS One 12, e0176717. https://doi.org/10.1371/journal.pone.0176717

Baragli, P., Gazzano, A., Martelli, F., Sighieri, C., 2009. How Do Horses Appraise Humans' Actions? A Brief Note over a Practical Way to Assess Stimulus Perception. J. Equine Vet. Sci. 29, 739-742. https://doi.org/10.1016/j.jevs.2009.08.006

Baragli, P., Padalino, B., Telatin, A., 2015. The role of associative and non-associative learning in the training of horses and implications for the welfare (a review). Ann. Ist. Super. Sanita 51, 40-51. https://doi.org/10.4415/ANN_15_01_08

Baragli, P., Vitale, V., Paoletti, E., Sighieri, C., Reddon, A.R., 2011. Detour behaviour in horses (Equus caballus). J. Ethol. 29, 227-234. https://doi.org/10.1007/s10164-010 0246-9

Baragli, P., Vitale, V., Sighieri, C., Lanata, A., Palagi, E., Reddon, A.R., 2017b. Consistency and flexibility in solving spatial tasks: different horses show different cognitive styles. Sci. Rep. 7, 16557. https://doi.org/10.1038/s41598-017-16729-z

Barnard, K., Brazelton, B., 1990. Touch: The foundation of experience: Full revised and expanded proceedings of Johnson \& Johnson pediatric round table X. International 
Universities Press, Inc, Madison.

Basile, M., Boivin, S., Boutin, A., Blois-Heulin, C., Hausberger, M., Lemasson, A., 2009. Socially dependent auditory laterality in domestic horses (Equus caballus). Anim. Cogn. 12, 611-619. https://doi.org/10.1007/s10071-009-0220-5

Bates, J.., 1989. Concepts and measures of temperament., in: Kohnstamm, G.A., Bates, J., Rothbart, M.. (Eds.), Temperament in Childhood. pp. 3-26.

Bateson, M., Matheson, S., 2007. Performance on a categorisation task suggests that removal of environmental enrichment induces "pessimism" in captive European starlings (Sturnus vulgaris). Anim. Welf. 16, 33-36.

Beerda, B., Schilder, M.B.., Van Hooff, J., De Vries, H.W., Mol, J.A., 1999. Chronic Stress in Dogs Subjected to Social and Spatial Restriction. I. Behavioral Responses. Physiol. Behav. 66, 233-242. https://doi.org/10.1016/S0031-9384(98)00289-3

Benefiel, A.C., Dong, W.K., Greenough, W.T., 2005. Mandatory “Enriched” Housing of Laboratory Animals: The Need for Evidence-based Evaluation. ILAR J. 46, 95-105. https://doi.org/10.1093/ilar.46.2.95

Benhajali, H., Richard-Yris, M.-A., Leroux, M., Ezzaouia, M., Charfi, F., Hausberger, M., 2008. A note on the time budget and social behaviour of densely housed horses: A case study in Arab breeding mares. Appl. Anim. Behav. Sci. 112, 196-200. https://doi.org/10.1016/J.APPLANIM.2007.08.007

Berkowitz, L., 1993. Pain and aggression: Some findings and implications. Motiv. Emot. 17, 277-293. https://doi.org/10.1007/BF00992223

Blokhuis, H. J., Jones, R. B., Geers, R., Miele, M., and Veissier, I. (2003). Measuring and monitoring animal welfare: transparency in the food product quality chain. Anim. Welf. $12,445-455$.

Boissy, A., 1995. Fear and fearfulness in animals. Quart. Rev. Biol., 70, 165-191

Boissy, A., Erhard, H.W., 2014. How Studying Interactions Between Animal Emotions, Cognition, and Personality Can Contribute to Improve Farm Animal Welfare. In Genetics and the Behavior of Domestic Animals (Second Edition)

Boissy, A., Manteuffel, G., Jensen, M.B., Moe, R.O., Spruijt, B., Keeling, L.J., Winckler, C., Forkman, B., Dimitrov, I., Langbein, J., Bakken, M., Veissier, I., Aubert, A., 2007. Assessment of positive emotions in animals to improve their welfare. Physiol. Behav. 92, 375-397. https://doi.org/10.1016/J.PHYSBEH.2007.02.003

Boivin, X., Garel, J.., Durier, C., Le Neindre, P., 1998. Is gentling by people rewarding for beef calves? Appl. Anim. Behav. Sci. 61, 1-12. https://doi.org/10.1016/S01681591(98)00170-1

Bourjade, M., de Boyer des Roches, A., Hausberger, M., 2009. Adult-Young Ratio, a Major Factor Regulating Social Behaviour of Young: A Horse Study. PLoS One 4, e4888. https://doi.org/10.1371/journal.pone.0004888

Boyd, L., Keiper, R., 2005. Behavioural ecology of feral horses, in: The Domestic Horse : The Origins, Developments, and Management of Its Behaviour. Cambridge University Press, p. 249.

Brajon, S., Laforest, J.-P., Schmitt, O., Devillers, N., 2015a. The Way Humans Behave 
Modulates the Emotional State of Piglets. PLoS One 10, e0133408.40 https://doi.org/10.1371/journal.pone.0133408

Brajon, S., Laforest, J.-P., Bergeron, R., Tallet, C., Devillers, N. 2015b. The perception of humans by piglets: Recognition of familiar humans and generalisation to unfamiliar humans. Animal Cognition, 18 (6), 1299-1316. Doi: 10.1007/s10071-015-0900-2.

Brando, S., Broom, D.M., Acasuso-Rivero, C., Clark, F., 2017. Optimal marine mammal welfare under human care: Current efforts and future directions. Behav. Processes. https://doi.org/10.1016/J.BEPROC.2017.09.011

Briefer, E., Maigrot, A.-L., Mandel, R., Freymond, S.B., Bachmann, I., Hillmann, E., 2015. Segregation of information about emotional arousal and valence in horse whinnies. Sci. Rep. 4, 9989. https://doi.org/10.1038/srep09989

Briefer Freymond, S., Briefer, E.F., Zollinger, A., Gindrat-von Allmen, Y., Wyss, C., Bachmann, I., 2014. Behaviour of horses in a judgment bias test associated with positive or negative reinforcement. Appl. Anim. Behav. Sci. 158, 34-45. https://doi.org/10.1016/J.APPLANIM.2014.06.006

Briefer Freymond, S., Ruet, A., Grivaz, M., Fuentes, C., Zuberbühler, K., Bachmann, I., Briefer, E.F., 2019. Stereotypic horses (Equus caballus) are not cognitively impaired. Anim. Cogn. 22, 17-33. https://doi.org/10.1007/s10071-018-1217-8

Broom, D.M., 1986. Responsiveness of stall-housed sows. Appl. Anim. Behav. Sci. 15, 186. https://doi.org/10.1016/0168-1591(86)90074-2

Broom, D.M., 1991. Animal welfare: concepts and measurement. Journal of Animal Science, $69,4167-4175$.

Brubaker, L., Udell, M.A.R., 2016. Cognition and learning in horses (Equus caballus): What we know and why we should ask more. Behav. Processes 126, 121-131. https://doi.org/10.1016/J.BEPROC.2016.03.017

Budras, K.D., Scheibe, K., Patan, B., Streich, W.J., Kim, K., 2001. Laminitis in Przewalski horses kept in a semireserve. J. Vet. Sci. 2, 1-7.

Budzynski, M., Soltys, L., Wawiorko, J., 1992. Estimate of excitability of half-bred horses in: 43 Annual Meeting FEZ, Madrid.

Burd, L., Kauffman, D.W., Kerbeshian, J., 1992. Tourette Syndrome and Learning Disabilities. J. Learn. Disabil. 25, 598-604. https://doi.org/10.1177/002221949202500909

Burn, C.C., Dennison, T.L., Whay, H.R., 2010. Relationships between behaviour and health in working horses, donkeys, and mules in developing countries. Appl. Anim. Behav. Sci. 126, 109-118. https://doi.org/10.1016/J.APPLANIM.2010.06.007

Cabib, S., Giardino, L., Calzà, L., Zanni, M., Mele, A., Puglisi-Allegra, S., 1998. Stress promotes major changes in dopamine receptor densities within the mesoaccumbens and nigrostriatal systems. Neuroscience 84, 193-200. https://doi.org/10.1016/S03064522(97)00468-5

Cairns, M.C., Cooper, J.J., Davidson, H.P.B., Mills, D.S., 2002. Association in horses of orosensory characteristics of foods with their post-ingestive consequences. Anim. Sci. 75, 257-265. https://doi.org/10.1017/s1357729800053017 
Camus, S.M., Rochais, C., Blois-Heulin, C., Li, Q., Hausberger, M., Bezard, E., 2013. Birth Origin Differentially Affects Depressive-Like Behaviours: Are Captive-Born Cynomolgus Monkeys More Vulnerable to Depression than Their Wild-Born Counterparts? PLoS One 8, e67711. https://doi.org/10.1371/journal.pone.0067711

Chaaya, N., Battle, A.R., Johnson, L.R., 2018. An update on contextual fear memory mechanisms: Transition between amygdala and hippocampus. Neuroscience and Biobehavioral Reviews, 92, 43-54. Doi: 10.1016/j.neubiorev.2018.05.013.

Chance, P., 1992. The Rewards of Learning. Phi Delta Kappan 72, 200-207.

Christensen, J.W., 2013. Object habituation in horses: The effect of voluntary versus negatively reinforced approach to frightening stimuli. Equine Vet. J. 45, 298-301. https://doi.org/10.1111/j.2042-3306.2012.00629.x

Chong, T.T.-J., 2018. Updating the role of dopamine in human motivation and apathy. Behavioral Sciences, Current Opinion in Behavioral Sciences, 22, 35-41.

Christensen, J.W., Ahrendt, L.P., Lintrup, R., Gaillard, C., Palme, R., Malmkvist, J., 2012. Does learning performance in horses relate to fearfulness, baseline stress hormone, and social rank? Appl. Anim. Behav. Sci. 140, 44-52. https://doi.org/10.1016/j.applanim.2012.05.003

Clarke, J.V., Nicol, C.J., Jones, R., McGreevy, P.D., 1996. Effects of observational learning on food selection in horses. Appl. Anim. Behav. Sci. 50, 177-184. https://doi.org/10.1016/0168-1591(96)01071-4

Clegg, H.A., Buckley, P., Friend, M.A., McGreevy, P.D., 2008. The ethological and physiological characteristics of cribbing and weaving horses. Appl. Anim. Behav. Sci. 109, 68-76. https://doi.org/10.1016/J.APPLANIM.2007.02.001

Clegg, I.L.K., Delfour, F., 2018. Cognitive judgement bias is associated with frequency of anticipatory behavior in bottlenose dolphins. Zoo Biol. https://doi.org/10.1002/zoo.21400

Clegg, I.L.K., Rödel, H.G., Cellier, M., Vink, D., Michaud, I., Mercera, B., Böye, M., Hausberger, M., Lemasson, A., Delfour, F., 2017. Schedule of Human-Controlled Periods Structures Bottlenose Dolphin (Tursiops truncatus) Behavior in Their FreeTime. J. Comp. Psychol. https://doi.org/10.1037/com0000059

Cloutier, S., Newberry, R.C., 2008. Use of a conditioning technique to reduce stress associated with repeated intra-peritoneal injections in laboratory rats. Appl. Anim. Behav. Sci. 112, 158-173. https://doi.org/10.1016/J.APPLANIM.2007.07.003

Concina, G., Renna, A., Grosso, A., Sacchetti, B., 2019. The auditory córtex and the emotional valence of sounds. Neuroscience and Biobehavioral Reviews, 98, 256-264. Doi: 10.1016/j.neubiorev.2019.01.018.

Cousillas, H., George, I., Henry, L., Richard, J.-P., Hausberger, M., 2008. Linking Social and Vocal Brains: Could Social Segregation Prevent a Proper Development of a Central Auditory Area in a Female Songbird? PLoS One 3, e2194. https://doi.org/10.1371/journal.pone.0002194

Cousillas, H., Oger, M., Rochais, C., Pettoello, C., Ménoret, M., Henry, S., Hausberger, M., 2017. An Ambulatory Electroencephalography System for Freely Moving Horses: An Innovating Approach. Front. Vet. Sci. 4, 57. https://doi.org/10.3389/fvets.2017.00057 
Cowan, N., 1997. Attention and memory. Oxford University Press.

Cronin, G.M., 1985. The development and significance of abnormal stereotyped behaviours in tethered sows. Agricultural University of Wageningen, Netherlands.

Dantzer, R., 1988. Les émotions. Presses Universitaires de Paris.

Davidson, R.J., 1992. Emotion and Affective Style: Hemispheric Substrates. Psychol. Sci. 3, 39-43. https://doi.org/10.1111/j.1467-9280.1992.tb00254.x

Darwin, C. (1872). The expression of the emotions in man and animals. Philosophi. New York.

Dawkins, M. S. (1990). From an animal's point of view: Motivation, fitness, and animal welfare. Behav.Brain Sci. 13, 1-9. doi:10.1017/S0140525X00077104.

Day, J.E.L., Van de Weerd, H.A., Edwards, S.A., 2008. The effect of varying lengths of straw bedding on the behaviour of growing pigs. Appl. Anim. Behav. Sci. 109, 249-260. https://doi.org/10.1016/J.APPLANIM.2007.02.006

De Boyer Des Roches, A., Richard-Yris, M.-A., Henry, S., Ezzaouïa, M., Hausberger, M., 2008. Laterality and emotions: Visual laterality in the domestic horse (Equus caballus) differs with objects' emotional value. Physiol. Behav. 94, 487-490. https://doi.org/10.1016/J.PHYSBEH.2008.03.002

de la Tourette, G., 1899. La maladie des tics convulsifs. La Sem. médicale 19, 153-156.

De Passille, A.M., Rushen, J., Ladewig, J., Petherick, C., Marie De Passillé, A., Rushen, J., Ladewig, J., Petherick, C., 1996. Dairy calves' discrimination of people based on previous handling Dairy Calves' Discrimination of People Based on Previous Handling 1. J. Anim. Sci 74, 969-974.

de Williams, A.C.C., 2002. Facial expression of pain, empathy, evolution, and social learning. Behav. Brain Sci. 25, 475-480.

Désiré, L., Boissy, A., Veissier, I., 2002. Emotions in farm animals: a new approach to animal welfare in applied ethology. Behav. Processes 60, 165-180. https://doi.org/10.1016/S0376-6357(02)00081-5

d'Ingeo' S., Quaranta' A., Siniscalchi'M., Stomp, M., Coste, C., Bagnard, C., Hausberger, M., Cousillas H., 2019. Horses associate individual human voices with the valence of past interactions: a behavioural and electrophysiological study. Scient. Rep., in press.

Dukas, R., 2004. Causes and Consequences of Limited Attention. Brain Behav Evol 63, 197210. https://doi.org/10.1159/000076781

Dumont, B., Boissy, A., 1999. Relations sociales et comportement alimentaire au pâturage. Prod. Anim. 1 (12), 3-10.

Durier, V., Henry, S., Sankey, C., Sizun, J., Hausberger, M., 2012. Locomotor Inhibition in Adult Horses Faced to Stressors: A Single Postpartum Experience May be Enough! Front. Psychol. 3, 442. https://doi.org/10.3389/fpsyg.2012.00442

Eccleston, C., 1994. Chronic pain and attention: A cognitive approach. Br. J. Clin. Psychol. 33, 535-547. https://doi.org/10.1111/j.2044-8260.1994.tb01150.x

Eccleston, C., Crombez, G., 1999. Pain Demands Attention: A Cognitive-Affective Model of 
the Interruptive Function of Pain. Psychol. Bull. 125, 356-366.

Ellis, S., Greening, L., 2016. Positively reinforcing an operant task using tactile stimulation and food - a comparison in horses using clicker training. J. Vet. Behav. Clin. Appl. Res. 15, 78. https://doi.org/10.1016/j.jveb.2016.08.008

Ernst, K., Puppe, B., Schön, P.C., Manteuffel, G., 2005. A complex automatic feeding system for pigs aimed to induce successful behavioural coping by cognitive adaptation. Appl. Anim. Behav. Sci. 91, 205-218. https://doi.org/10.1016/J.APPLANIM.2004.10.010

Farmer, K., Krueger, K., Byrne, R.W., Byrne, R.W., 2010. Visual laterality in the domestic horse (Equus caballus) interacting with humans. Anim. Cogn. 13, 229-238. https://doi.org/10.1007/s10071-009-0260-x

Feh, C., 2005. Relationships and communication in socially natural horse herds, in: Mills, D.S., McDonnell, S.. (Eds.), The Domestic Horse: The Origins, Development, and Management of Its Behaviour. Cambridge University Press, pp. 83-93.

Feh, C., de Mazierès, J., 1993. Grooming at a preferred site reduces heart rate in horses. Anim. Behav. https://doi.org/10.1006/anbe.1993.1309

Ferguson, D., Rosales-Ruiz, J., 2001. Loading the problem loader: the effect of target and training and shaping on trailer-loading behavior of horses. J. Appl. Behav. Anal. 34, 409-424.

Fiske, J.C., Potter, G.D., 1979. Discrimination Reversal Learning in Yearling Horses. J. Anim. Sci. 49, 583-588.

Forkman, B., Boissy, A., Meunier-Salaün, M.C., Canali, E., Jones, R.B., 2007. A critical review of fear tests used on cattle, pigs, sheep, poultry and horses. Physiology \& Behavior 92: 3, 340-374. Doi: 10.1016/j.physbeh.2007.03.016.

Fordham, D.P., Al-Gahtani, S., Durotoye, L.A., Rodway, R.G., 1991. Changes in plasma cortisol and $\beta$-endorphin concentrations and behaviour in sheep subjected to a change of environment. Anim. Prod. 52, 287-296. https://doi.org/10.1017/S0003356100012794

Forgas, J.P., 2000. Introduction: the role of affect in social cognition, in: Forgas, J.P. (Ed.), Feeling and Thinking: The Role of Affect in Social Cognition. Cambridge, pp. 1-28.

Fureix, C., Beaulieu, C., Argaud, S., Rochais, C., Quinton, M., Hausberger, M., Mason, G., 2015. Investigating anhedonia in a non-conventional species: do some riding horses Equus caballus display symptoms of depression? Appl. Anim. Behav. Sci. 162, 26-36.

Fureix, C., Bourjade, M., Henry, S., Sankey, C., Hausberger, M., 2012a. Exploring aggression regulation in managed groups of horses Equus caballus. Appl. Anim. Behav. Sci. 138, 216-228. https://doi.org/10.1016/j.applanim.2012.02.009

Fureix, C., Gorecka-Bruzda, A., Gautier, E., Hausberger, M., 2011a. Cooccurrence of Yawning and Stereotypic Behaviour in Horses (Equus caballus). ISRN Zool. 10. https://doi.org/10.5402/2011/271209

Fureix, C., Hausberger, M., Seneque, E., Morisset, S., Baylac, M., Cornette, R., Biquand, V., Deleporte, P., 2011b. Geometric morphometrics as a tool for improving the comparative study of behavioural postures. Naturwissenschaften 98, 583. https://doi.org/10.1007/s00114-011-0803-2

Fureix, C., Jego, P., Henry, S., Lansade, L., Hausberger, M., 2012b. Towards an Ethological 
Animal Model of Depression? A Study on Horses. PLoS One 7, e39280.

https://doi.org/10.1371/journal.pone.0039280

Fureix, C., Jego, P., Sankey, C., Hausberger, M., 2009. How horses (Equus caballus) see the world: humans as significant "objects." Anim. Cogn. 12, 643-654.

https://doi.org/10.1007/s10071-009-0223-2

Fureix, C., Meagher, R.K., 2015. What can inactivity (in its various forms) reveal about affective states in non-human animals? A review. Appl. Anim. Behav. Sci. 171, 8-24. https://doi.org/10.1016/J.APPLANIM.2015.08.036

Fureix, C., Menguy, H., Hausberger, M., 2010. Partners with Bad Temper: Reject or Cure? A Study of Chronic Pain and Aggression in Horses. PLoS One 5, e12434. https://doi.org/10.1371/journal.pone.0012434

Gabor, V., Gerken, M., 2012. Cognitive testing in horses using a computer based apparatus. Appl. Anim. Behav. Sci. 139, 242-250. https://doi.org/10.1016/j.applanim.2012.04.010

Gardner, L.P., 1933. The responses of horses to the situation of a closed feed box. J. Comp. Psychol. 15, 445-467. https://doi.org/10.1037/h0074308

Garner, J.P., Meehan, C.L., Mench, J.A., 2003. Stereotypies in caged parrots, schizophrenia and autism: evidence for a common mechanism. Behav. Brain Res. 145, 125-134. https://doi.org/10.1016/S0166-4328(03)00115-3

Goeders, N.E., Guerin, G.F., 1994. Non-contingent electric footshock facilitates the acquisition of intravenous cocaine self-administration in rats. Psychopharmacology 114, 63-70.

Goldsmith, H.H., Buss, A.H., Plomin, R., Rothbart, M.K., Thomas, A., Chess, S., Hinde, R.A., McCall, R.B., 1987. Roundtable: What Is Temperament? Four Approaches. Child Dev. 58, 505. https://doi.org/10.2307/1130527

Goldstein, D.S., 2010. Adrenal response to stress. Cellular and Molecular Neurobiology, 30 (8), 1433-1440. Doi: 10.1007/s10571-010-9606-9.

Goodwin, D., Davidson, H.P.B., Harris, P., 2007. A note on behaviour of stabled horses with foraging devices in mangers and buckets. Appl. Anim. Behav. Sci. 105, 238-243. https://doi.org/10.1016/J.APPLANIM.2006.05.018

Gotlib, I.H., Joormann, J., 2010. Cognition and Depression: Current Status and Future Directions. Annu. Rev. Clin. Psychol. 6, 285-312. https://doi.org/10.1146/annurev.clinpsy.121208.131305

Grandin, T., Irlbeck, N., Philips, M., 1996. The advantages of training atemopes to cooperate with veterinary procedures, in: Aquarium and Zoological Association (AZA) Conference Proceedings. p. 562.

Grassé, P.., 1963. Les phénomènes sociaux chez les animaux. Cah. l'Institut Sci. économiques appliquée supplément 139, 7-23.

Gray, J.A., 1987. The Psychology of Fear and Stress, second ed. Cambridge University Press, Cambridge.

Griffin, D.R., 1984. Animal thinking. Harvard University press, Cambridge, MA.

Grosso, A., Cambiaghi, M., Concina, G., Sacco, T., Sacchetti, B., 2015. Auditory córtex 
involvement in emotional learning and memory. Neuroscience, 299:45-55. Doi: 10.1016/j.neuroscience.2015.04.068.

Guarna, M., Ghelardini, C., Galeotti, N., Bartolini, A., Noli, L., Neri, C., Stefano, G.B., Bianchi, E., 2004. Effects of endogenous morphine deprivation on memory retention of passive avoidance learning in mice. Int. J. Neuropsychopharmacol. 7, 311-319. https://doi.org/10.1017/S1461145704004341

Gubernick, D., Klopfer, P., 2013. Parental care in mammals. Springer Science \& Business Media.

Hagemann, D., Waldstein, S.R., Thayer, J.F., 2003. Central and autonomic nervous system integration in emotion. Brain and Cognition, 52, 79-87. Doi: 10.1016/S02782626(03)00011-3.

Hall, C., Goodwin, D., Heleski, C., Randle, H., Waran, N., 2008. Is There Evidence of Learned Helplessness in Horses? J. Appl. Anim. Welf. Sci. 11, 249-266. https://doi.org/10.1080/10888700802101130

Hanggi, E.B., 2005. The Thinking Horse: Cognition and Perception Reviewed. AAEP Proc. $51,246-255$.

Hanggi, E.B., 2003. Discrimination learning based on relative size concepts in horses (Equus caballus). Appl. Anim. Behav. Sci. 83, 201-213. https://doi.org/10.1016/S01681591(03)00136-9

Hanggi, E.B., 1999. Categorization learning in horses (Equus caballus). J. Comp. Psychol. 113, 243-252. https://doi.org/10.1037/0735-7036.113.3.243

Hanggi, E.B., Ingersoll, J.F., 2009. Stimulus discrimination by horses under scotopic conditions. Behav. Processes 82, 45-50. https://doi.org/10.1016/J.BEPROC.2009.04.009

Harding, E.J., Paul, E.S., Mendl, M., 2004. Animal behavior-cognitive bias and affective state. Nature 427, 312.

Harlow, H.F., Dodsworth, R.O., Harlow, M.K., 1965. Total social isolation in monkeys. Proc. Natl. Acad. Sci. U. S. A. 54, 90-7. https://doi.org/10.1073/PNAS.54.1.90

Harlow, H.F., Suomi, S.J., 1974. Induced depression in monkeys. Behav. Biol. 12, 273-296. https://doi.org/10.1016/S0091-6773(74)91475-8

Hart, R.P., Martelli, M.F., Zasler, N.D., 2000. Chronic Pain and Neuropsychological Functioning. Neuropsychol. Rev. 10, 131-149. https://doi.org/10.1023/A:1009020914358

Hausberger, M., Bruderer, C., Le Scolan, N., Pierre, J.-S., 2004. Interplay between environmental and genetic factors in temperament/personality traits in horses (Equus caballus). J. Comp. Psychol. 118, 434-446.

Hausberger, M., Fureix, C., Lesimple, C., 2016. Detecting horses' sickness: in search of visible signs. Appl. Anim. Behav. Sci. 175, 41-49. https://doi.org/10.1016/J.APPLANIM.2015.09.005

Hausberger, M., Gautier, E., Biquand, V., Lunel, C., Jégo, P., 2009. Could work be a source of behavioural disorders? A Study in horses. PLoS One 4, e7625.

https://doi.org/10.1371/journal.pone.0007625 
Hausberger, M., Gautier, E., Müller, C., Jego, P., 2007a. Lower learning abilities in stereotypic horses. Appl. Anim. Behav. Sci. 107, 299-306. https://doi.org/10.1016/J.APPLANIM.2006.10.003

Hausberger, M., Henry, S., 2018. Equine sensory systems. Encycl. Anim. Cogn. Behav.

Hausberger, M., Muller, C., 2002. A brief note on some possible factors involved in the reactions of horses to humans. Appl. Anim. Behav. Sci. 76, 339-344. https://doi.org/10.1016/S0168-1591(02)00016-3

Hausberger, M., Muller, C., Lunel, C., 2011. Does Work Affect Personality? A Study in Horses. PLoS One 6, e14659. https://doi.org/10.1371/journal.pone.0014659

Hausberger, M., Richard-Yris, M.-A., Henry, L., 1995. Song sharing reflects the social organization in a captive group of European starlings (Sturnus vulgaris). J. Comp. Psychol. 109, 222.

Hausberger, M., Richard-Yris, M.-A., Ricard, A., 2007b. Interplay between environmental and genetic factors in the behaviour of horses. Publ. Assoc. Anim. Prod. 23, 122.

Hausberger, M., Roche, H., Henry, S., Visser, E.K., 2008. A review of the human-horse relationship. Appl. Anim. Behav. Sci. 109, 1-24. https://doi.org/10.1016/J.APPLANIM.2007.04.015

Haussler, K.K., 1996. The lower back and pelvis of performance horses receive a closer look. J. Equine Vet. Sci. 16, 279-281. https://doi.org/10.1016/S0737-0806(96)80220-6

Haverbeke, A., Laporte, B., Depiereux, E., Giffroy, J.-M., Diederich, C., 2008. Training methods of military dog handlers and their effects on the team's performances. Appl. Anim. Behav. Sci. 113, 110-122. https://doi.org/10.1016/J.APPLANIM.2007.11.010

Heird, J.C., Lokey, C.E., Cogan, D.C., 1986. Repeatability and comparison of two maze tests to measure learning ability in horses. Appl. Anim. Behav. Sci. 16, 103-119. https://doi.org/10.1016/0168-1591(86)90103-6

Heleski, C., Wickens, C., Minero, M., DallaCosta, E., Wu, C., Czeszak, E., Köenig von Borstel, U., 2015. Do soothing vocal cues enhance horses' ability to learn a frightening task? J. Vet. Behav. Clin. Appl. Res. 10, 41-47. https://doi.org/10.1016/J.JVEB.2014.08.009

Hemmings, A., McBride, S.D., Hale, C.E., 2007. Perseverative responding and the aetiology of equine oral stereotypy. Appl. Anim. Behav. Sci. 104, 143-150. https://doi.org/10.1016/J.APPLANIM.2006.04.031

Henninger, M.S.H., Ohl, F., Hölter, S.M., Weissenbacher, P., Toschi, N., Lörscher, P., Wigger, A., Spanagel, R., Landgraf, R., 2000. Unconditioned anxiety and social behaviour in two rat lines selectively bred for high and low anxiety-related behaviour. Behv. Brain Res. 111, 153-163

Hemsworth, P.H., Barnett, J.L., 1987. Human-animal interactions. Vet. Clin. North Am. Food Anim. Pract. 3, 339-56.

Hemsworth, P.H., Coleman, G.J., 1998. Human-Livestock Interactions : the Stockperson and the Productivity and Welfare of Intensively Farmed Animals. CABI.

Henry, S., Fureix, C., Rowberry, R., Bateson, M., Hausberger, M., 2017. Do horses with poor welfare show "pessimistic" cognitive biases? Sci. Nat. 104, 8. 
https://doi.org/10.1007/s00114-016-1429-1

Henry, S., Hemery, D., Richard, M.-A., Hausberger, M., 2005. Human-mare relationships and behaviour of foals toward humans. Appl. Anim. Behav. Sci. 93, 341-362. https://doi.org/10.1016/J.APPLANIM.2005.01.008

Henry, S., Richard-Yris, M.-A., Hausberger, M., 2006. Influence of various early human-foal interferences on subsequent human-foal relationship. Dev. Psychobiol. 48, 712-718. https://doi.org/10.1002/dev.20189

Henry, S., Richard-Yris, M.-A., Tordjman, S., Hausberger, M., 2009. Neonatal Handling Affects Durably Bonding and Social Development. PLoS One 4, e5216. https://doi.org/10.1371/JOURNAL.PONE.0005216

Herron, M.A., Martin, J.E., Joyce, J.R., 1978. Quantitative study of the decussating optic axons in the pony, cow, sheep, and pig. Am. J. Vet. Res. 39, 1137-9.

Hiby, E., Rooney, N., Bradshaw, J., 2004. Dog training methods: their use, effectiveness and interaction with behaviour and welfare. Anim. Welf. 13, 63-69.

Hinde, R.A., 1985. Was "The expression of the emotions" a misleading phrase? Anim. Behav. 33, 985-992. https://doi.org/10.1016/S0003-3472(85)80032-4

Hinde, R.A., 1979. Towards understanding relationships. Academic Press, Londres.

Hinde, R.A., 1976. Interactions, Relationships and Social Structure. Man 11, 1. https://doi.org/10.2307/2800384

Hinde, R.A., Stevenson-Hinde, J., 1968. Constraints on learning : limitations and predispositions. Academic Press.

Hockenhull, J., Creighton, E., 2013. Training horses: Positive reinforcement, positive punishment, and ridden behavior problems. J. Vet. Behav. Clin. Appl. Res. 8, 245-252. https://doi.org/10.1016/j.jveb.2012.06.002

Holden, M.D., Gregory, J., Watkins, V., Radford, L., 2006. Operant-conditioning programme for White rhinoceros, Black rhinoceros and Indian or Greater one-horned Asian rhinoceros Ceratotherium simum, Diceros bi cornis and Rhinoceros unicornis at Whipsnade Wild Animal Park, Dunstable, UK. Int. Zoo Yearb. 40, 144-149. https://doi.org/10.1111/j.1748-1090.2006.00144.x

Hopfinger, J.B., Mangun, G.R., 2001. Electrophysiological Studies of Reflexive Attention. Adv. Psychol. 133, 3-26. https://doi.org/10.1016/S0166-4115(01)80003-0

Hothersall, B., Gale, E. V., Harris, P., Nicol, C.J., 2010. Cue use by foals (Equus caballus) in a discrimination learning task. Anim. Cogn. 13, 63-74. https://doi.org/10.1007/s100711529 009-0245-9

Houpt, K.A., Zahoric, D.., Swartzman-Andert, J.., 1990. Taste aversion learning in horses. J. Anim. Sci. 68, 2340-2344.

Hoyamoun, H., Khavandgar, S., Zarrindast, M.R., 2003. Morphine state-dependent learning: interactions with $\alpha 2$-adrenoceptors and acute stress. Behav. Pharmacol. 14, 41-48.

Innes, L., McBride, S., 2008. Negative versus positive reinforcement: An evaluation of training strategies for rehabilitated horses. Appl. Anim. Behav. Sci. 112, 357-368. https://doi.org/10.1016/J.APPLANIM.2007.08.011 
Jago, J.., Krohn, C.., Matthews, L.., 1999. The influence of feeding and handling on the development of the human-animal interactions in young cattle. Appl. Anim. Behav. Sci. 62, 137-151. https://doi.org/10.1016/S0168-1591(98)00219-6

Jeffcott, L.B., 1979. Back Problems in the Horse-A look at past, present and future progress. Equine Vet. J. 11, 129-136. https://doi.org/10.1111/j.2042-3306.1979.tb01324.x

Jensen, K.H., Pedersen, L.J., Nielsen, E.K., Heller, K.E., Ladewig, J., Jørgensen, E., 1996. Intermittent stress in pigs: Effects on behavior, pituitary - Adrenocortical axis, growth, and gastric ulceration. Physiol. Behav. 59, 741-748. https://doi.org/10.1016/00319384(95)02159-0

Jones, M.W., Wilson, M.A., 2005. Theta Rhythms Coordinate Hippocampal-Prefrontal Interactions in a Spatial Memory Task. PLoS Biol. 3, e402. https://doi.org/10.1371/journal.pbio.0030402

Kabadayi, C., Bobrowicz, K., Osvath, M., 2018. The detour paradigm in animal cognition. Anim. Cogn. 21, 21-35. https://doi.org/10.1007/s10071-017-1152-0

Kewman, D.G., Vaishampayan, N., Zald, D., Han, B., 1991. Cognitive Impairment in Musculoskeletal Pain Patients. Int. J. Psychiatry Med. 21, 253-262. https://doi.org/10.2190/FRYK-TMGA-AULW-BM5G

Kiley-Worthington, M., 1976. The Tail Movements of Ungulates, Canids and Felids With Particular Reference To Their Causation and Function as Displays. Behaviour 56, 69114. https://doi.org/10.1163/156853976X00307

Kirkden, R.D., Pajor, E.A., 2006. Using preference, motivation and aversion tests to ask scientific questions about animals' feelings. Appl. Anim. Behav. Sci. 100, 29-47. https://doi.org/10.1016/J.APPLANIM.2006.04.009

Kirsty, R., Andrew, H., Meriel, M.-C., Catherine, H., 2015. Cognitive differences in horses performing locomotor versus oral stereotypic behaviour. Appl. Anim. Behav. Sci. 168, 37-44. https://doi.org/10.1016/j.applanim.2015.04.015

König von Borstel, U., Visser, E., Hall, C., 2017. Indicators of stress in equitation. Appl. Anim. Behav. Sci. 190, 43-56. https://doi.org/10.1016/j.applanim.2017.02.018

Kotrschal, A., Taborsky, B., 2010. Environmental Change Enhances Cognitive Abilities in Fish. PLoS Biol. 8, e1000351. https://doi.org/10.1371/journal.pbio.1000351

Kozak,K., Lucatch, A.M., Lowe, D.J.E., Balodis, I.M., MacKillop, J.T, . George, P., 2018 The.neurobiology of impulsivity and substance use disorders: implications for treatment Ann. N. Y. Acad. Sci. (2018), pp. 1-21 https://nyaspubs.onlinelibrary.wiley.com/doi/full/10.1111/nyas.13977

Krapp, A., 1999. Interest, motivation and learning: An educational-psychological perspective. Eur. J. Psychol. Educ. https://doi.org/10.2307/23420114

Krueger, K., 2007. Behaviour of horses in the "round pen technique." Appl. Anim. Behav. Sci. 104, 162-170. https://doi.org/10.1016/J.APPLANIM.2006.04.021

Krueger, K., Farmer, K., Heinze, J., 2014. The effects of age, rank and neophobia on social learning in horses. Anim Cogn 17, 645-655. https://doi.org/10.1007/s10071-013-0696-X

Krueger, K., Flauger, B., Farmer, K., Maros, K., 2011. Horses (Equus caballus) use human local enhancement cues and adjust to human attention. Anim. Cogn. 14, 187-201. 
https://doi.org/10.1007/s10071-010-0352-7

Krueger, K., Marr, I., Farmer, K., 2017. Equine cognition. Encycl. Anim. Cogn. Behav.

Kuhl, P.K., 2003. Human speech and birdsong: communication and the social brain. Proc. Natl. Acad. Sci. U. S. A. 100, 9645-6. https://doi.org/10.1073/pnas.1733998100

Lampe, J.F., Andre, J., 2012. Cross-modal recognition of human individuals in domestic horses (Equus caballus). Anim. Cogn. 15, 623-630. https://doi.org/10.1007/s10071-0120490-1

Lansade, L., Bouissou, M.-F., 2008. Reactivity to humans: A temperament trait of horses which is stable across time and situations. Appl. Anim. Behav. Sci. 114, 492-508. https://doi.org/10.1016/J.APPLANIM.2008.04.012

Lansade, L., Coutureau, E., Marchand, A., Baranger, G., Valenchon, M., Calandreau, L., 2013. Dimensions of Temperament Modulate Cue-Controlled Behavior: A Study on Pavlovian to Instrumental Transfer in Horses (Equus Caballus). PLoS One 8, e64853. https://doi.org/10.1371/journal.pone.0064853

Lansade, L., Marchand, A.R., Coutureau, E., Ballé, C., Polli, F., Calandreau, L., 2017. Personality and predisposition to form habit behaviours during instrumental conditioning in horses (Equus caballus). PLoS One 12. https://doi.org/10.1371/journal.pone.0171010

Lansade, L., Simon, F., 2010. Horses' learning performances are under the influence of several temperamental dimensions. Appl. Anim. Behav. Sci. 125, 30-37. https://doi.org/10.1016/J.APPLANIM.2010.02.010

Lansade, L., Valenchon, M., Foury, A., Neveux, C., Cole, S.W., Layé, S., Cardinaud, B., Lévy, F., Moisan, M.-P., 2014. Behavioral and Transcriptomic Fingerprints of an Enriched Environment in Horses (Equus caballus). PLoS One 9, e114384. https://doi.org/10.1371/journal.pone.0114384

Larose, C., Richard-Yris, M.-A., Hausberger, M., Rogers, L., 2006. Laterality of horses associated with emotionality in novel situations. Laterality Asymmetries Body, Brain, Cogn. 11, 355-367. https://doi.org/10.1080/13576500600624221

Le Scolan, N., Hausberger, M., Wolff, A., 1997. Stability over situations in temperamental traits of horses as revealed by experimental and scoring approaches. Behav. Processes 41, 257-266. https://doi.org/10.1016/S0376-6357(97)00052-1

Lebelt, D., Zanella, A.J., Unshelm, J., 1998. Physiological correlates associated with cribbing behaviour in horses: changes in thermal threshold, heart rate, plasma $\beta$-endorphin and serotonin. Equine Vet. J. 30, 21-27. https://doi.org/10.1111/j.2042-3306.1998.tb05140.x

Leblanc, M.-A., 2010. The mind of the horse : an introduction to equine cognition. Harvard University press.

Leckman, J.F., 2002. Tourette's syndrome. Lancet 360, 1577-1586. https://doi.org/10.1016/S0140-6736(02)11526-1

LeDoux, J.E., 2000. Emotion circuit in the brain. Annual Review of Neuroscience, 23, 155184. Doi: 10.1146/annurev.neuro.23.1.155.

Lee, J., Floyd, T., Erb, H., Houpt, K., 2011. Preference and demand for exercise in stabled horses. Appl. Anim. Behav. Sci. 130, 91-100.

https://doi.org/10.1016/j.applanim.2011.01.001 
Leiner, L. and Fendt, M. (2011) Behavioral fear and heart rate responses in horses after exposure to novel objects, effects of habituation, Applied Animal Behavior Science, 13:104-109.

Leliveld, L.M.C., Langbein, J., Puppe, B., 2013. The emergence of emotional lateralization: Evidence in non-human vertebrates and implications for farm animals. Appl. Anim. Behav. Sci. 145, 1-14. https://doi.org/10.1016/J.APPLANIM.2013.02.002

Lemasson, A., Boutin, A., Boivin, S., Blois-Heulin, C., Hausberger, M., 2009. Horse (Equus caballus) whinnies: a source of social information. Anim. Cogn. 12, 693-704. https://doi.org/10.1007/s10071-009-0229-9

Lemasson, A., Remeuf, K., Hausberger, M., 2015a. Tenseness relaxed by vocalizing, illustrated by horses (Equus caballus) whinnying. J. Comp. Psychol. 129, 311-315. https://doi.org/10.1037/a0039032

Lemasson, A., Remeuf, K., Trabalon, M., Cuir, F., Hausberger, M., 2015b. Mares prefer the voices of highly fertile stallions. PLoS One 10, e0118468. https://doi.org/10.1371/journal.pone.0118468

Lerner, J.S., Keltner, D., 2000. Beyond valence: Toward a model of emotion-specific influences on judgement and choice. Cogn. Emot. 14, 473-493. https://doi.org/10.1080/026999300402763

Lesimple, C., Fureix, C., Aubé, L., Hausberger, M., 2016a. Detecting and measuring back disorders in nonverbal individuals: the example of domestic horses. Anim. Behav. Cogn. 3, 159-179. https://doi.org/10.12966/abc.05.08.2016

Lesimple, C., Fureix, C., Biquand, V., Hausberger, M., 2013. Comparison of clinical examinations of back disorders and humans' evaluation of back pain in riding school horses. BMC Vet. Res. 9, 209. https://doi.org/10.1186/1746-6148-9-209

Lesimple, C., Fureix, C., De Margerie, E., Sénèque, E., Menguy, H., Hausberger, M., 2012. Towards a Postural Indicator of Back Pain in Horses (Equus caballus). PLoS One 7, e44604. https://doi.org/10.1371/journal.pone.0044604

Lesimple, C., Fureix, C., LeScolan, N., Richard-Yris, M.-A., Hausberger, M., 2011. Housing conditions and breed are associated with emotionality and cognitive abilities in riding school horses. Appl. Anim. Behav. Sci. 129, 92-99. https://doi.org/10.1016/J.APPLANIM.2010.11.005

Lesimple, C., Fureix, C., Menguy, H., Hausberger, M., 2010. Human direct actions may alter animal welfare, a study on horses (Equus caballus). PLoS One 5, e10257. https://doi.org/10.1371/journal.pone.0010257

Lesimple, C., Poissonnet, A., Hausberger, M., 2016b. How to keep your horse safe? An epidemiological study about management practices. Appl. Anim. Behav. Sci. 181, 105114. https://doi.org/10.1016/J.APPLANIM.2016.04.015

Lesimple, C., Sankey, C., Richard, M.A., Hausberger, M., 2012. Do Horses Expect Humans to Solve Their Problems? Front. Psychol. 3, 306. https://doi.org/10.3389/fpsyg.2012.00306

Lihoreau, M., Brepson, L., Rivault, C., 2009. The weight of the clan: Even in insects, social isolation can induce a behavioural syndrome. Behav. Processes 82, 81-84. https://doi.org/10.1016/J.BEPROC.2009.03.008 
Lima, A., Lemasson, A., Boye, M., Hausberger, M., 2017. Vocal activities reflect the temporal distribution of bottlenose dolphin social and non-social activity in a zoological park. Zoo Biol. 36, 351-359. https://doi.org/10.1002/zoo.21387

Lindberg, A.., Kelland, A., Nicol, C.., 1999. Effects of observational learning on acquisition of an operant response in horses. Appl. Anim. Behav. Sci. 61, 187-199.

https://doi.org/10.1016/S0168-1591(98)00184-1

Lowe, S.E., Bradshaw, J.W.S., 2001. Ontogeny of individuality in the domestic cat in the home environment. Anim. Behav. 61, 231-237.

https://doi.org/10.1006/ANBE.2000.1545

Macleod, C., Mathews, A., Tata, P., 1986. Attentional bias in emotional disorders. J. Abnorm. Psychol. 95, 15-20.

Mader, D.R., Price, E.O., 1980. Discrimination mearning in horses: effects of breed, age and social dominance. J. Anim. Sci. 50, 962-965.

Maigrot, A.-L., Hillmann, E., Anne, C., Briefer, E.F., 2017. Vocal expression of emotional valence in Przewalski's horses (Equus przewalskii). Sci. Rep. 7, 8779. https://doi.org/10.1038/s41598-017-09437-1

Makowska, L.J., Weary, D., 2013. Assessing the emotions of laboratory rats. Appl. Anim. Behav. Sci. 148, 1-12

Malavasi, R., Huber, L., 2016. Evidence of heterospecific referential communication from domestic horses (Equus caballus) to humans. Anim. Cogn. 19, 899-909. https://doi.org/10.1007/s10071-016-0987-0

Mao, C.P., Zhang, Q.L., Bao, F.X., Liao, X., Yang, X.L., Zhang, M., 2014. Decreased activation of cingulo-frontal-parietal cognitive/attention network during an attentiondemanding task in patients with chronic low back pain. Neuroradiology 56, 903-912. https://doi.org/10.1007/s00234-014-1391-6

Marinier, S., Alexander, A.J., 1994. The use of a maze in testing learning and memory in horses. Appl. Anim. Behav. Sci. 39, 177-182.

Maros, K., Gácsi, M., Miklósi, Á., 2008. Comprehension of human pointing gestures in horses (Equus caballus). Anim. Cogn. 11, 457-466. https://doi.org/10.1007/s10071-0080136-5

Marsh, R., Alexander, G.M., Packard, M.G., Zhu, H., Wingard, J.C., Quackenbush, G., Peterson, B.S., 2004. Habit Learning in Tourette Syndrome. Arch. Gen. Psychiatry 61, 1259. https://doi.org/10.1001/archpsyc.61.12.1259

Mason, G.J., 1991. Stereotypies: a critical review. Anim. Behav. 41, 1015-1037. https://doi.org/10.1016/S0003-3472(05)80640-2

Mason, G.J., Latham, N., 2004. Can't stop, won't stop: is stereotypy a reliable animal welfare indicator? Anim. Welf. 13, 57-69.

Mason, W.., 1978. Ontogeny of social systems, in: Chivers, D.., Herbert, J. (Eds.), Recent Advances in Primatology. San Diego, pp. 5-14.

Mathews, A., MacLeod, C., 2002. Induced processing biases have causal effects on anxiety. Cogn. Emot. 16, 331-354. https://doi.org/10.1080/02699930143000518 
Mathews, A., MacLeod, C., 1994. Cognitive Approaches to Emotion and Emotional Disorders. Annu. Rev. Psychol. 45, 25-50. https://doi.org/10.1146/annurev.ps.45.020194.000325

Matthews, G.R., Antes, J.R., 1992. Visual attention and depression: Cognitive biases in the eye fixations of the dysphoric and the nondepressed. Cognit. Ther. Res. 16, 359-371. https://doi.org/10.1007/BF01183287

McBride, S.D., Hemmings, A., 2005. Altered mesoaccumbens and nigro-striatal dopamine physiology is associated with stereotypy development in a non-rodent species. Behav. Brain Res. 159, 113-118. https://doi.org/10.1016/J.BBR.2004.10.014

McCall, C.A., 2007. Making equine learning research applicable to training procedures. Behav. Processes 76, 27-28.

McCracken, L.M., Iverson, G.L., 2001. Predicting complaints of impaired cognitive functioning in patients with chronic pain. J. Pain Symptom Manage. 21, 392-6. https://doi.org/10.1016/S0885-3924(01)00267-6

McDonnell, S.M., 2000. How to rehabilitate horses with injection shyness (or any procedure non-compliance). AEEP Procee 46, 166-172.

McGreevy, P., McLean, A., 2005. The behavioural problems with the ridden horse, in: The Domestic Horse: The Origins, Development, and Management of Its Behaviour. Cambrige university press, pp. 196-211.

McGreevy, P., McLean, A., Buckley, P., McConaghy, F., McLean, C., 2011. How riding may affect welfare: What the equine veterinarian needs to know. Equine Vet. Educ. 23, 531539. https://doi.org/10.1111/j.2042-3292.2010.00217.x

McGreevy, P.D., Cripps, P.J., French, N.P., Green, L.E., Nicol, C.J., 1995. Management factors associated with stereotypic and redirected behaviour in the Thoroughbred horse. Equine Vet. J. 27, 86-91. https://doi.org/10.1111/j.2042-3306.1995.tb03041.x

McGreevy, P.D., Nicol, C.J., 1998. Prevention of crib-biting: a review. Equine Vet. J. 30, 3538. https://doi.org/10.1111/j.2042-3306.1998.tb05143.x

McKinley, J., Buchanan-Smith, H.M., Bassett, L., Morris, K., 2003. Training common marmosets (Callithrix jacchus) to cooperate during routine laboratory procedures: ease of training and time investment. J. Appl. Anim. Welf. Sci. 6, 209-220.

McLean, A.N., Christensen, J.W., 2017. The application of learning theory in horse training. Appl. Anim. Behav. Sci. 190, 18-27. https://doi.org/10.1016/j.applanim.2017.02.020

McLean, A.N., Christensen, J.W., 2017. The application of learning theory in horse training. Appl. Anim. Behav. Sci. 190, 18-27. https://doi.org/10.1016/J.APPLANIM.2017.02.020

McLean, A.N., McGreevy, P.D., 2010. Horse-training techniques that may defy the principles of learning theory and compromise welfare. J. Vet. Behav. Clin. Appl. Res. 5, 187-195. https://doi.org/10.1016/j.jveb.2010.04.002

Mejdell, C.M., Buvik, T., Jørgensen, G.H.M., Bøe, K.E., 2016. Horses can learn to use symbols to communicate their preferences. Appl. Anim. Behav. Sci. 184, 66-73. https://doi.org/10.1016/j.applanim.2016.07.014

Mellen, J.D., Ellis, S., 1996. Animal learning and husbandry training, in: Wild Mammals in Captivity: Principles and Techniques. 
Menant, O., Destrez, A., Deiss, V., Boissy, A., Delagrange, P., Calandreau, L., Chaillou, E., 2016, Régulation des émotions chez l'animal d'élevage : focus sur les acteurs neurobiologiques. Inra Production Animale, 29 (4), 241-254.

Menant, O., Prima, M.-C., Morisse, M., Cornilleau, F., Moussu, C., Gautier, A., Blanchon, H., Meurisse, M., Delagrange, P., Tillet, Y., Chaillou, E., 2018. First evidence of neuronal connections between specific parts of the periaqueductal gray (PAG) and the rest of the brain in sheep: placing the sheep PAG in the circuit of emotion. Brain Structure and Function, 223, 3297-3316. Doi: 10.1007/s00429-018-1689-y.

Mendl, M., Burman, O.H.P., Parker, R.M.A., Paul, E.S., 2009. Cognitive bias as an indicator of animal emotion and welfare: Emerging evidence and underlying mechanisms. Appl. Anim. Behav. Sci. 118, 161-181. https://doi.org/10.1016/J.APPLANIM.2009.02.023

Mendl, M., Burman, O.H.P., Paul, E.S., 2010. An integrative and functional framework for the study of animal emotion and mood. Proceedings. Biol. Sci. 277, 2895-904. https://doi.org/10.1098/rspb.2010.0303

Mills, D., 2000. Thoroughbred bedding preferences, associated behaviour differences and their implications for equine welfare. Anim. Sci. 70, 95-106. https://doi.org/10.1017/S1357729800051638

Mills, D.S., 2005. Repetitive movement problems in the horse, in: Cambridge university press (Ed.), The Domestic Horse: The Origins, Development, and Management of Its Behaviour. pp. 212-227.

Mineka, S., Watson, D., Clark, L.A., 1998. Comorbidity of anxiety and unipolar mood disorders. Annu. Rev. Psychol. 49, 377-412. https://doi.org/10.1146/annurev.psych.49.1.377

Moe, R.O., Bakken, M., Kittilsen, S., Kingsley-Smith, H., Spruijt, B.M., 2006. A note on reward-related behaviour and emotional expressions in farmed silver foxes (Vulpes vulpes) Basis for a novel tool to study animal welfare. Appl. Anim. Behav. Sci. 101, 362368. https://doi.org/10.1016/J.APPLANIM.2006.02.004

Munoz, M., Esteve, R., 2005. Reports of memory functioning by patients with chronic pain. Clin. J. Pain 21, 287-291.

Murphy, J., Arkins, S., 2007. Equine learning behaviour. Behav. Processes 76, 1-13. https://doi.org/10.1016/J.BEPROC.2006.06.009

Nagasawa, M., Mitsui, S., En, S., Ohtani, N., Ohta, M., Sakuma, Y., Onaka, T., Mogi, K., Kikusui, T., 2015. Social evolution. Oxytocin-gaze positive loop and the coevolution of human-dog bonds. Science 348, 333-6. https://doi.org/10.1126/science.1261022

Nettle, D., Bateson, M., 2012. The Evolutionary Origins of Mood and Its Disorders. Curr. Biol. 22, R712-R721. https://doi.org/10.1016/J.CUB.2012.06.020

Nicol, C., 1999. Understanding equine stereotypies. Equine Vet. J. 31, 20-25. https://doi.org/10.1111/j.2042-3306.1999.tb05151.x

Nicol, C.., 2002. Equine learning: progress and suggestions for future research. Appl. Anim. Behav. Sci. 78, 193-208. https://doi.org/10.1016/S0168-1591(02)00093-X

Nisticò, G., Stephenson, J.D., Montanini, S., Marmo, E., 1981. Behavioral and electrocortical effects of beta-endorphin after intracerebral infusion in rats. J. Med. 12, 463-74. 
Normando, S., Meers, L., Samuels, W.E., Faustini, M., Ödberg, F.O., 2011. Variables affecting the prevalence of behavioural problems in horses. Can riding style and other management factors be significant? Appl. Anim. Behav. Sci. 133, 186-198. https://doi.org/10.1016/J.APPLANIM.2011.06.012

Nurnberg, H.G., Keith, S.J., Matt Paxton, D., 1997. Consideration of the relevance of ethological animal models for human repetitive behavioral spectrum disorders. Biol. Psychiatry 41, 226-229. https://doi.org/10.1016/S0006-3223(96)00100-X

Onton, J., Delorme, A., Makeig, S., 2005. Frontal midline EEG dynamics during working memory. Neuroimage 27, 341-356. https://doi.org/10.1016/J.NEUROIMAGE.2005.04.014

Pais-Vieira, M., Lima, D., Galhardo, V., 2009. Sustained attention deficits in rats with chronic inflammatory pain. Neurosci. Lett. 463, 98-102. https://doi.org/10.1016/J.NEULET.2009.07.050

Pajor, E.., Rushen, J., de Passillé, A.M.., 2003. Dairy cattle's choice of handling treatments in a Y-maze. Appl. Anim. Behav. Sci. 80, 93-107. https://doi.org/10.1016/S01681591(02)00119-3

Pajor, E.., Rushen, J., de Passillé, A.M.., 2000. Aversion learning techniques to evaluate dairy cattle handling practices. Appl. Anim. Behav. Sci. 69, 89-102. https://doi.org/10.1016/S0168-1591(00)00119-2

Panksepp, J., 2005. Affective neuroscience: The foundations of human and animal emotions. Series in Affective Science, Oxford University Press, Oxford, UK.

Panksepp, J., 2011a. The basic emotional circuits of mammalian brains: Do animals have affected lives? Neuroscience and Behavioral Reviews, 35, 1791-1804.

Panksepp, J., Fuchs, T., Iacobucci, P., 2011b. The basic neuroscience of emotional experiences in mammals: The case of subcortical FEAR circuitry and implications for clinical anxiety. Applied Animal Behaviour Science, 129, 1-17. Doi: 10.1016/j.applanim.2010.09.014.

Parker, M., McBride, S.D., Redhead, E.S., Goodwin, D., 2009. Differential place and response learning in horses displaying an oral stereotypy. Behav. Brain Res. 200, 100105. https://doi.org/10.1016/J.BBR.2008.12.033

Parker, M., Redhead, E.S., Goodwin, D., McBride, S.D., 2008. Impaired instrumental choice in crib-biting horses (Equus caballus). Behav. Brain Res. 191, 137-140. https://doi.org/10.1016/J.BBR.2008.03.009

Paul, E.S., Harding, E.J., Mendl, M., 2005. Measuring emotional processes in animals: the utility of a cognitive approach. Neurosci. Biobehav. Rev. 29, 469-491. https://doi.org/10.1016/J.NEUBIOREV.2005.01.002

Pavlov, I.P., 1927. Conditional reflexes: an investigation of the physiological activity of the cerebral cortex. Oxford university press.

Pavlov, I.P., 1904. The physiology of digestion. Nobel lecture (Physiology ore Medecine), Elsevier. ed. Amsterdam.

Pawluski, J., Jego, P., Henry, S., Bruchet, A., Palme, R., Coste, C., Hausberger, M., 2017. Low plasma cortisol and fecal cortisol metabolite measures as indicators of compromised 
welfare in domestic horses (Equus caballus). PLoS One 12, e0182257.

https://doi.org/10.1371/journal.pone.0182257

Peters, S.M., Bleijenberg, E.H., van Dierendonck, M.C., van der Harst, J.E., Spruijt, B.M., 2012. Characterization of anticipatory behaviour in domesticated horses (Equus caballus). Appl. Anim. Behav. Sci. 138, 60-69.

https://doi.org/10.1016/J.APPLANIM.2012.01.018

Pfister, J.A., Stegelmeier, B.L., Cheney, C.D., Ralphs, M.H., Gardner, D.R., 2002. Conditioning taste aversions to locoweed (Oxytropis sericea) in horses. J Anim Sci. USDA Natl Agric. Libr. March J. Anim. Sci 21, 79-83.

Pfungst, 0, 1911. Clever Hans. The horse of Mr. von Osten: A Contribution to Experimental Animal and Human Psychology, Henry Holt. ed. Rinehart and Winston, New York.

Popescu, S., Diugan, E.-A., 2013a. The relationship between behavioral and other welfare indicators of working horses. J. Equine Vet. Sci. 33, 1-12. https://doi.org/10.1016/j.jevs.2012.04.001

Popescu, S., Diugan, E.-A., 2013b. The Relationship Between Behavioral and Other Welfare Indicators of Working Horses. J. Equine Vet. Sci. 33, 1-12. https://doi.org/10.1016/J.JEVS.2012.04.001

Posner, M., Snyder, C.R., Davidson, B.J., 1980. Attention and the detection of signals. J. Exp. Psychol. Gen. 109, 160-174.

Powell, S.B., Newman, H.A., Pendergast, J.F., Lewis, M.H., 1999. A Rodent Model of Spontaneous Stereotypy: Initial Characterization of Developmental, Environmental, and Neurobiological Factors. Physiol. Behav. 66, 355-363.

https://doi.org/10.1016/S00319384(98)00303-5

Price, J., Catriona, S., Welsh, E.M., Waran, N.K., 2003. Preliminary evaluation of a behaviour-based system for assessment of post-operative pain in horses following arthroscopic surgery. Vet. Anaesth. Analg. 30, 124-137.

https://doi.org/10.1046/j.14672995.2003.00139.x

Pritchard, J.C., Lindberg, A.C., Main, D.C.J., Whay, H.R., 2005. Assessment of the welfare of working horses, mules and donkeys, using health and behaviour parameters. Prev. Vet. Med. 69, 265-283. https://doi.org/10.1016/J.PREVETMED.2005.02.002

Proops, L., McComb, K., 2010. Attributing attention: the use of human-given cues by domestic horses (Equus caballus). Anim. Cogn. 13, 197-205. https://doi.org/10.1007/s10071-009-0257-5

Ramirez, K., 2012. Marine mammal training: the history of training animals for medical behaviors and keys to their success. Vet. Clin. North Am. Exot. Anim. Pract. 15, 413-23. https://doi.org/10.1016/j.cvex.2012.06.005

Reinhardt, V., 2003. Working With Rather Than Against Macaques During Blood Collection. J. Appl. Anim. Welf. Sci. 6, 189-197.

Rihs, T.A., Michel, C.M., Thut, G., 2007. Mechanisms of selective inhibition in visual spatial attention are indexed by ?-band EEG synchronization. Eur. J. Neurosci. 25, 603-610. https://doi.org/10.1111/j.1460-9568.2007.05278.x

Rivera, E., Benjamin, S., Nielsen, B., Shelle, J., Zanella, A.J., 2002. Behavioral and 
physiological responses of horses to initial training: the comparison between pastured versus stalled horses. Appl. Anim. Behav. Sci. 78, 235-352.

Rochais, C., Fureix, C., Lesimple, C., Hausberger, M., 2016a. Lower attention to daily environment: a novel cue for detecting chronic horses' back pain? Sci. Rep. 6, 20117. https://doi.org/10.1038/srep20117

Rochais, C., Henry, S., Fureix, C., Hausberger, M., 2016b. Investigating attentional processes in depressive-like domestic horses (Equus caballus). Behav. Processes 124, 93-96. https://doi.org/10.1016/J.BEPROC.2015.12.010

Rochais, C., Henry, S., Hausberger, M., 2018. "Hay-bags" and "Slow feeders": Testing their impact on horse behaviour and welfare. Appl. Anim. Behav. Sci. 198, 52-59. https://doi.org/10.1016/j.applanim.2017.09.019

Rochais, C., Henry, S., Hausberger, M., 2017a. Spontaneous attention-capture by auditory distractors as predictor of distractibility: a study of domestic horses (Equus caballus). Sci. Rep. 7, 15283. https://doi.org/10.1038/s41598-017-15654-5

Rochais, C., Henry, S., Sankey, C., Nassur, F., Góracka-Bruzda, A., Hausberger, M., 2014. Visual attention, an indicator of human-animal relationships? A study of domestic horses (Equus caballus). Front. Psychol. 5, 108. https://doi.org/10.3389/fpsyg.2014.00108

Rochais, C., Sébilleau, M., Houdebine, M., Bec, P., Hausberger, M., Henry, S., 2017b. A novel test for evaluating horses' spontaneous visual attention is predictive of attention in operant learning tasks. Sci. Nat. 104, 61. https://doi.org/10.1007/s00114-017-1480-6

Rochais, C., Sébilleau, M., Menoret, M., Oger, M., Henry, S., Hausberger, M., Cousillas, H., 2018. Attentional state and brain processes: state-dependent lateralization of EEG profiles in horses. Sci. Rep. 8, 10153. https://doi.org/10.1038/s41598-018-28334-9

Rogers, L., Andrew, R., 2002. Comparative Vertebrate Lateralization. Cambridge University Press.

Rogers, L.J., 2010. Relevance of brain and behavioural lateralization to animal welfare. Appl. Anim. Behav. Sci. 127, 1-11. https://doi.org/10.1016/J.APPLANIM.2010.06.008

Röhrs, V.M., Ebinger, P., 1993. Progressive und regressive Hirngrößienveränderungen bei Equiden. J. Zool. Syst. Evol. Res. 31, 233-239. https://doi.org/10.1111/j.14390469.1993.tb00192.x

Roitblat, H.L., Bever, T.G., H.S., T., 1984. Animal cognition, Lawrence E. ed. London.

Roitblat, H.L., von Fersen, L., 1992. Comparative cognition: representations and processes in learning and memory. Annu. Rev. Psychol. 43, 671-710. https://doi.org/10.1146/annurev.ps.43.020192.003323

Rolls, E.T., 2019. The orbitofrontal cortex and emotion in health and disease, including depression. Neuropsychologia, 128, 14-43. Doi: 10.1016/j.neuropsychologia.2017.09.021.

Rørvang, M.V., Ahrendt, L.P., Christensen, J.W., 2015. Horses fail to use social learning when solving spatial detour tasks. Anim Cogn 18, 847-854. https://doi.org/10.1007/s10071-015-0852-6

Russell, J.A., 1980. A circumplex model of affect. J. Pers. Soc. Psychol. 39, 1161-1178. 
Russell, J., Barrett, L.F., 1999. Core affect, prototypical emotional episodes, and other things called emotion: Dissecting the elephant. J. Pers. Soc. Psychol. 76, 805-819.

Sankey, C., Henry, S., André, N., Richard-Yris, M.-A., Hausberger, M., 2011a. Do Horses Have a Concept of Person? PLoS One 6, e18331. https://doi.org/10.1371/journal.pone.0018331

Sankey, C., Henry, S., Clouard, C., Richard-Yris, M.-A., Hausberger, M., 2011b. Asymmetry of behavioral responses to a human approach in young naive vs. trained horses. Physiol. Behav. 104, 464-468. https://doi.org/10.1016/J.PHYSBEH.2011.05.009

Sankey, C., Henry, S., Górecka-Bruzda, A., Richard-Yris, M.-A., Hausberger, M., 2010a. The Way to a Man's Heart Is through His Stomach: What about Horses? PLoS One 5, e15446. https://doi.org/10.1371/journal.pone.0015446

Sankey, C., Richard-Yris, M.-A., Henry, S., Fureix, C., Nassur, F., Hausberger, M., 2010 b. Reinforcement as a mediator of the perception of humans by horses (Equus caballus). Anim. Cogn. 13, 753-765. https://doi.org/10.1007/s10071-010-0326-9

Sankey, C., Richard-Yris, M.-A., Leroy, H., Henry, S., Hausberger, M., 2010c. Positive interactions lead to lasting positive memories in horses, Equus caballus. Anim. Behav. 79, 869-875. https://doi.org/10.1016/J.ANBEHAV.2009.12.037

Sappington, B.K.F., McCall, C.A., Coleman, D.A., Kuhlers, D.L., Lishak, R.S., 1997. A preliminary study of the relationship between discrimination reversal learning and performance tasks in yearling and 2-year-old horses. Appl. Anim. Behav. Sci. 53, $157-$ 166. https://doi.org/10.1016/S0168-1591(96)01157-4

Saslow, C.A., 2002. Understanding the perceptual world of horses. Appl. Anim. Behav. Sci. 78, 209-224. https://doi.org/10.1016/S0168-1591(02)00092-8

Scherer, K.R., 2005. What are emotions? And how can they be measured? Soc. Sci. Inf. 44, 695-729. https://doi.org/10.1177/0539018405058216

Scherer, K.R., 1984. On the nature and function of emotion: a component process approach, in: KR, S., P, E. (Eds.), Approaches to Emotion. Hillsdale: Lawrence Erlbaum, pp. 297317.

Schmidt, A., Aurich, J., Möstl, E., Müller, J., Aurich, C., 2010. Changes in cortisol release and heart rate and heart rate variability during the initial training of 3-year-old sport horses. Horm. Behav. 58, 628-636. https://doi.org/10.1016/J.YHBEH.2010.06.011

Sénèque, E., Lesimple, C., Morisset, S., Hausberger, M., 2019. Could posture reflect welfare state? A study using geometric morphometrics in riding school horses. PLoS One 14, e0211852. https://doi.org/10.1371/journal.pone.0211852

Shettleworth, S., 1998. Cognition, evolution and behavior. Oxford University Press.

Skinner, B.F., 1976. About Behaviourism, Jonathan C. ed. Vintage.

Skinner, B.F., 1938. The behaviour of organisms, Appleton-C. ed. Appleton-Century- Crofts, New York.

Slater, C., Dymond, S., 2011. Using differential reinforcement to improve equine welfare: Shaping appropriate truck loading and feet handling. Behav. Processes 86, 329-339. https://doi.org/10.1016/J.BEPROC.2011.02.001 
Slotow, R., van Dyk, G., Poole, J., Page, B., Klocke, A., 2000. Older bull elephants control young males. Nature 408, 425-426. https://doi.org/10.1038/35044191

Smith, A.V., Proops, L., Grounds, K., Wathan, J., McComb, K., 2016. Functionally relevant responses to human facial expressions of emotion in the domestic horse (Equus caballus). Biol. Lett. 12, 20150907. https://doi.org/10.1098/rsbl.2015.0907

Smith, T.W., Ingram, R.E., Roth, D.L., 1985. Self-focused attention and depression: Selfevaluation, affect, and life stress. Motiv. Emot. 9, 381-389.

https://doi.org/10.1007/BF00992207

Søndergaard, E., Bak Jensen, M., Nicol, C.J., 2011. Motivation for social contact in horses measured by operant conditioning. Appl. Anim. Behav. Sci. 132, 131-137. https://doi.org/10.1016/j.applanim.2011.04.007

Søndergaard, E., Halekoh, U., 2003. Young horses' reactions to humans in relation to handling and social environment. Appl. Anim. Behav. Sci. 84, 265-280. https://doi.org/10.1016/J.APPLANIM.2003.08.011

Søndergaard, E., Ladewig, J., 2004. Group housing exerts a positive effect on the behaviour of young horses during training. Appl. Anim. Behav. Sci. 87, 105-118.

https://doi.org/10.1016/J.APPLANIM.2003.12.010

Soudry, Y., Lemogne, C., Malinvaud, D., Consoli, S.-M., Bonfils, P., 2011. Olfactory system and emotion: Common substrates. European Annals of Otorhinolaryngology, Head and Neck Diseases, 128, 18-23. Doi: 10.1016/j.anorl.2010.09.007.

Spruijt, B.M., van den Bos, R., Pijlman, F.T.A., 2001. A concept of welfare based on reward evaluating mechanisms in the brain: anticipatory behaviour as an indicator for the state of reward systems. Appl. Anim. Behav. Sci. 72, 145-171. https://doi.org/10.1016/S01681591(00)00204-5

Staddon, J.E.., 1983. Adaptive behaviour and learning. Cambridge University Press.

Stomp, M., Leroux, M., Cellier, M., Henry, S., Lemasson, A., Hausberger, M., 2018. An unexpected acoustic indicator of positive emotions in horses. PLoS One 13, e0197898. https://doi.org/10.1371/journal.pone.0197898

Storch, K.-F., Weitz, C.J., 2009. Daily rhythms of food-anticipatory behavioral activity do not require the known circadian clock. Proc. Natl. Acad. Sci. U. S. A. 106, 6808-13. https://doi.org/10.1073/pnas.0902063106

Stukenborg, A., Traulsen, I., Puppe, B., Presuhn, U., Krieter, J., 2011. Agonistic behaviour after mixing in pigs under commercial farm conditions. Appl. Anim. Behav. Sci. 129, 28-35. https://doi.org/10.1016/J.APPLANIM.2010.10.004

Swann, W.J., 2006. Improving the welfare of working equine animals in developing countries. Appl. Anim. Behav. Sci. 100, 148-151. https://doi.org/10.1016/J.APPLANIM.2006.04.001

Symes, C.T., Perrin, M.R., 2003. Feeding biology of the Greyheaded Parrot, Poicephalusfuscicollis suahelicus (Reichenow), in Northern Province, South Africa. Emu - Austral. Ornithol. 103, 49-58. https://doi.org/10.1071/MU01038

Tallet, C., Brajon, S., Devillers, N., Lensink, J., 2018. Pig-human interactions, in: Advances in Pig Welfare. Elsevier, pp. 381-398. https://doi.org/10.1016/B978-0-08- 
1010129.00008-3

Timberlake, W., 1990. Natural learning in laboratory paradigms., in: Contemporary Issues in Comparative Psychology. Sinauer Associates, Sunderland, pp. 31-54. https://doi.org/10.1037/11525-002

Topál, J., Miklósi, Á., Csányi, V., 1997. Dog-human relationship affects problem solving behavior in the dog. Anthrozoos 10, 214-224.

Trifilieff, P., Ducrocq, F., van der Veldt, S., Martinez, D., 2017. Blunted dopamine transmission in addiction: Potential mechanisms and implications for behavior. Seminars in Nuclear Biology, 47, 64-74. Doi: 10.1053/j.semnuclmed.2016.09.003.

Uller, C., Lewis, J., 2009. Horses (Equus caballus) select the greater of two quantities in small numerical contrasts. Anim. Cogn. 12, 733-738. https://doi.org/10.1007/s100711971 009-0225-0

Valenchon, M., Lévy, F., Fortin, M., Leterrier, C., Lansade, L., 2013a. Stress and temperament affect working memory performance for disappearing food in horses, Equus caballus. Anim. Behav. 86, 1233-1240. https://doi.org/10.1016/J.ANBEHAV.2013.09.026

Valenchon, M., Lévy, F., Górecka-Bruzda, A., Calandreau, L., Lansade, L., $2013 b$. Characterization of long-term memory, resistance to extinction, and influence of temperament during two instrumental tasks in horses. Anim Cogn 16, 1001-1006. https://doi.org/10.1007/s10071-013-0648-5

Valenchon, M., Lévy, F., Moussu, C., Lansade, L., 2017. Stress affects instrumental learning based on positive or negative reinforcement in interaction with personality in domestic horses. PLoS One 12, e0170783. https://doi.org/10.1371/journal.pone.0170783

Valenchon, M., Lévy, F., Prunier, A., Moussu, C., Calandreau, L., Lansade, L., 2013c. Stress Modulates Instrumental Learning Performances in Horses (Equus caballus) in Interaction with Temperament. PLoS One 8, e62324. https://doi.org/10.1371/journal.pone.0062324

Vallortigara, G., Rogers, L.J., 2005. Survival with an asymmetrical brain: Advantages and disadvantages of cerebral lateralization. Behav. Brain Sci. 28, 575-633.

van Rooijen, J., 1982. The value of choice tests in assessing welfare of domestic animals. Appl. Anim. Ethol. 8, 295-299.

Vasconcellos, A. da S., Virányi, Z., Range, F., Ades, C., Scheidegger, J.K., Möstl, E., Kotrschal, K., 2016. Training Reduces Stress in Human-Socialised Wolves to the Same Degree as in Dogs. PLoS One 11, e0162389.

https://doi.org/10.1371/journal.pone.0162389

Vinke, C.M., Van Den, R.B., Spruijt, B.M., 2004. Anticipatory activity and stereotypical behaviour in American mink (Mustela vison) in three housing systems differing in the amount of enrichments. Appl. Anim. Behav. Sci. 89, 145-161. https://doi.org/10.1016/J.APPLANIM.2004.06.002

Visser, E.., van Reenen, C.., Schilder, M.B.., Barneveld, A., Blokhuis, H.., 2003. Learning performances in young horses using two different learning tests. Appl. Anim. Behav. Sci. 80, 311-326. https://doi.org/10.1016/S0168-1591(02)00235-6 
Visser, E.K., Ellis, A.D., Van Reenen, C.G., 2008. The effect of two different housing conditions on the welfare of young horses stabled for the first time. Appl. Anim. Behav. Sci. 114, 521-533. https://doi.org/10.1016/J.APPLANIM.2008.03.003

Visser, E.K., VanDierendonck, M., Ellis, A.D., Rijksen, C., Van Reenen, C.G., 2009. A comparison of sympathetic and conventional training methods on responses to initial horse training. Vet. J. 181, 48-52. https://doi.org/10.1016/J.TVJL.2009.03.009

Von Borstel, U., Heatly Duncan, I. J., Shoveller, A. K., Merkies, K., Keeling, L. J., Millman, S. T., 2009. Impact of riding in coercively obtained Rollkür posture on welfare and fear in performance horse. Appl. Anim. Behav. Sci., 116, 228-236. doi:

10.1016/j.applanim.2008.10.001

von Uexküll, 1965. Monde Animaux et Monde Humain, suivi de la Theorie de la Signification, Gonthier. ed. Paris.

Waiblinger, S., Boivin, X., Pedersen, V., Tosi, M.-V., Janczak, A.M., Visser, E.K., Jones, 2011 R.B., 2006. Assessing the human-animal relationship in farmed species: A critical review. Appl. Anim. Behav. Sci. 101, 185-242. https://doi.org/10.1016/j.applanim.2006.02.001

Waring, G.H., 2003. Horse behavior. The behavioral traits and adaptations of domestic and wild horses, including ponies. Horse Behav. Behav. Trait. Adapt. Domest. wild horses, Incl. ponies.

Warren-Smith, A.K., McGreevy, P.D., 2008. Preliminary Investigations Into the Ethological Relevance of Round-Pen (Round-Yard) Training of Horses. J. Appl. Anim. Welf. Sci. 11, 285-298. https://doi.org/10.1080/10888700802101304

Warren-Smith, A.K., McGreevy, P.D., 2007. The use of blended positive and negative reinforcement in shaping the halt response of horses (Equus caballus). Anim. Welf. 16, 481.

Wathan, J., McComb, K., 2014. The eyes and ears are visual indicators of attention in domestic horses. Curr. Biol. 24, R677-R679. https://doi.org/10.1016/J.CUB.2014.06.023

Watson, D., Wiese, D., Vaidya, J., Tellegen, A., 1999. The two general activation systems of affect: Structural findings, evolutionary considerations, and psychobiological evidence. J. Pers. Soc. Psychol. 76, 820-838.

Watson, J.C., McDonnell, S.M., 2018. Effects of three non-confrontational handling techniques on the behavior of horses during a simulated mildly aversive veterinary procedure. Appl. Anim. Behav. Sci. 203, 19-23. https://doi.org/10.1016/J.APPLANIM.2018.02.007

Watters, J. V., 2014. Searching for behavioral indicators of welfare in zoos: Uncovering anticipatory behavior. Zoo Biol. 33, 251-256. https://doi.org/10.1002/zoo.21144

Whay, H., Main, D., Green, L., and Webster, A. (2003). Observations and investigation of farm. Vet. Rec. 153, 197-202.

Whisher, L., Raum, M., Pina, L., Pérez, L., Erb, H., Houpt, C., Houpt, K., 2011. Effects of environmental factors on cribbing activity by horses. Appl. Anim. Behav. Sci. 135, 6369. https://doi.org/10.1016/J.APPLANIM.2011.09.001

Williams, J.M., Watts, F.N., MacLeod, C., Mathews, A., 1997. Cognitive psychology and 
emotional disorders, Wiley, J. ed. Chichester.

Wolff, A., Hausberger, M., 1996. Learning and memorisation of two different tasks in horses: the effects of age, sex and sire. Appl. Anim. Behav. Sci. 46, 137-143. https://doi.org/10.1016/0168-1591(95)00659-1

Wolff, A., Hausberger, M., Le Scolan, N., 1997. Experimental tests to assess emotionality in horses. Behav. Processes 40, 209-221. https://doi.org/10.1016/S0376-6357(97)00784-5

Wood, J.,1998. Quality assurance schemes. Meat Sci. 49, 191-203.

Würbel, H., 2001. Ideal homes? Housing effects on rodent brain and behaviour. Trends Neurosci. 24, 207-211. https://doi.org/10.1016/S0166-2236(00)01718-5

Würbel, H., 2000. Behaviour and the standardization fallacy. Nat. Genet. 26, 263-263. https://doi.org/10.1038/81541

Yoerg, S., Kamil, A., 1991. Integrating cognitive ethology with cognitive psychology, in: Cognitive Ethology: The Minds of Other Animals : Essays in Honor of Donald R. Griffin. L. Erlbaum Associates, p. 332. 